Universidade de São Paulo

Faculdade de Odontologia de Ribeirão Preto

Departamento de Clínica Infantil, Odontologia Preventiva e Social

\title{
INFLUÊNCIA DA IRRADIAÇÃO COM COBALTO-60 NAS PROPRIEDADES MECÂNICAS, QUÍMICAS E MORFOLÓGICAS DO ESMALTE E DA DENTINA DE DENTES DECÍDUOS - ESTUDO IN VITRO
}

Talitha de Siqueira Mellara

Ribeirão Preto 2011 
Talitha de Siqueira Mellara

\section{INFLUÊNCIA DA IRRADIAÇÃO COM COBALTO-60 NAS PROPRIEDADES MECÂNICAS, QUÍMICAS E MORFOLÓGICAS DO ESMALTE E DA DENTINA DE DENTES DECÍDUOS - ESTUDO IN VITRO}

Dissertação apresentada à Faculdade de Odontologia de Ribeirão Preto da Universidade de São Paulo, para obtenção do Título de Mestre em Odontopediatria.

Orientador: Profa. Dra. Alexandra Mussolino de Queiroz 
AUTORIZO A REPRODUÇÃO E DIVULGAÇÃO TOTAL OU PARCIAL DESTE TRABALHO, POR QUALQUER MEIO CONVENCIONAL OU ELETRÔNICO, PARA FINS DE ESTUDO E PESQUISA, DESDE QUE CITADA A FONTE.

\title{
FICHA CATALOGRÁFICA
}

\begin{abstract}
Mellara, Talitha de Siqueira
Influência da irradiação com cobalto-60 nas propriedades mecânicas, químicas e morfológicas do esmalte e da dentina de dentes decíduos Estudo in vitro. Ribeirão Preto, 2010.

$$
77 \text { p. : il. ; } 30 \mathrm{~cm}
$$
\end{abstract}

Dissertação de Mestrado, apresentada à Faculdade de Odontologia de Ribeirão Preto/USP - Área de concentração: Odontopediatria.

Orientador: Queiroz, Alexandra Mussolino

1. Radioterapia 2. Cobalto 60 3. Cárie de radiação 4. Microdureza 5. Dentes decíduos 6. Composição química 7. Morfologia 


\title{
INFLUÊNCIA DA IRRADIAÇÃO COM COBALTO-60 NAS PROPRIEDADES MECÂNICAS, QUÍMICAS E MORFOLÓGICAS DO ESMALTE E DA DENTINA DE DENTES DECÍDUOS - ESTUDO IN VITRO
}

\author{
Dissertação apresentada à Faculdade de \\ Odontologia de Ribeirão Preto da Universidade de São \\ Paulo, para obtenção do Título de Mestre em \\ Odontopediatria.
}

Data da defensa

Banca Examinadora

Prof(a).

$\operatorname{Dr}(\mathrm{a})$ :

Instituicao:

Julgamento: Assinatura:

$\operatorname{Prof}(a) \cdot \operatorname{Dr}(a)$ :

Instituicao:

Julgamento: Assinatura:

Prof(a). $\operatorname{Dr}(a)$.:

Instituicao:

Julgamento: Assinatura: 


\section{DADOS CuRRICULARES}

\section{Talitha de Siqueira Mellara}

Nascimento

Filiação

2001-2004

2007-2009

2009-2011
19 de Setembro de 1981 - Ribeirão Preto, São Paulo

José Antonio Mellara

Julita Maria de Siqueira Mellara

Curso de Graduação

Faculdade de Odontologia de Ribeirão Preto da Universidade de São Paulo

Especialização em Odontopediatria Associação Odontológica de Ribeirão Preto

Curso de Pós-Graduação (Mestrado) em Odontologia Área de Concentração: Odontopediatria

Faculdade de Odontologia de Ribeirão Preto/USP 


\section{Dedicatória}

À Deus por ter me guiado, me protegido e iluminado meu caminho. Obrigada pelos exemplos que recebi, e pela força que me deu os momentos de desânimos.

À meus pais J osé Antonio Mellara e J ulita Maria de Siqueira Mellara, por ser os dois grandes pilares da minha vida. Pelo amor incondicional e por todo apoio que me deram nesses anos. Pelos en sinamentos e exemplo de vida. 0 incentivo, dedicação e ainda mais pela fé que depositaram em mim, por ser essas pessoas que me fazem ir sempre para frente. Este esforço e esta conquista são seus também. Simplesmente eu os amo. E essa conquista é tão de vocês quanto minha.

Ao meu imão Thiago de Siqueira Mellara, pelo apoio, amor, força e incentivo. Agradeço por poder dividir com você várias coisas da minha vida. Amo você!

Ao meu namorado Rafael Candido Pedroso e Silva que me apoiou, incentivou e me deu forças para continuar, mesmo nas horas de desanimo. Obrigada pelo seu amor e carin ho.

À todos os familiares e amigos que sempre torceram por mim e me deram carinho! 


\section{Agradecimen tos Especiais}

À minha orientadora Profa. Dra. Alexandra Mussolino de Queiroz, exemplo de dedicação e amor à profissão. Meu agradecimento pelos ensinamentos, humildade e simpatia. Obrigada por transmitir seus conhecimentos e experiências profissionais e da vida com muito carinho. Expresso meu sincero agradecimen to e meu profun do respeito, que sempre serão poucos diante do muito que me ofereceu. Danda, Obrigada por ter acreditado em mim. Nunca poderei retribuir tamanha consideração e carinho, mas lembre se que sempre terá meu respeito e admiração, por tudo que me en sinou e pelas oportunidades que me deu.

Ten ho muito orgulho de ter sido sua aluna, sempre serei uma grande admiradora sua..........

Ao cirugião-dentista Francisco Wanderlay Garcia de Paula e Silva, pela forma atenciosa e carinhosa que teve para comigo desde 0 momento em que me conheceu, pela alegria, otimismo e dedicação, pela sua amizade, as conversas agradáveis e os momentos gratos, por me apoiar e me ajudar muito nessa fase da vida, agradeço todos os dias a D eus por ter te colocado em meu caminho e poder ver como existem pessoas amigas de verdade. OBRIGADA FRAN!!

Sem o apoio de vocês eu não teria chegado tão longe, vocês tomaram minha jomada muito mais agradável, nunca quero perder o carinho de vocês, sou etemamen te grata.... 


\section{Agradecimen tos}

À Profa. Dra. Léa Assed Bezerra da Silva, por ter me recebido e acolhido na Odontopediatria. Obrigada por acreditar na minha capacidade e pelo in centivo constan te de apren dizado e a pesquisa.

À Profa. Dra. Raquel Assed Bezerra da Silva, obrigada pela confiança, por acreditar em mim, pelos incentivos que me ajudam a crescer e melhorar em muitos aspectos da minha vida, por abrir as portas do teu coração, por ser um exemplo de mulher, uma gran de amiga e uma excelente pessoa.

À Prof. Dr. Paulo Nelson Filho, pelo estimulo, dedicação e paciência ao transmitir seus conhecimentos e experiências, pela disposição que tem sempre para todos seus alunos e pela simpatia e alegria que tran sformaram o trabalho em bons momentos, obrigada por ter me ajudado nesta jomada.

À Profa. Dra. Regina Guenka Palma-Dibb, do Departamento de Odontologia Restauradora da Faculdade de Odontologia de Riberão Preto da Universidade de São Paulo, pelo apoio oferecido, pelas oportunidades de contribuição cientifica e pela fundamental colaboração para realização deste trabalho. Professora obrigada por abrir a porta do seu laboratório para que eu pudesse trabalhar e ter acreditado em mim.

Ao Prof. Dr. Harley Francisco de Olivera, do Departamento de Clínica Médica, da Faculdade de Medicina de Ribeirão Preto da Universidade de São Paulo, pelas oportunidades de contribuição científica, pelo apoio oferecido e pela fundamental colaboração para realização deste trabalho. Professor obrigada por ter acreditado em mim e por todo con hecimen to e orien tação. 
À Profa. Dra. Kranya Victória Díaz Serrano, pela agradável convivência, por ser essa pessoa sempre disponível, pelo incentivo e o apoio. Pela sua alegria otimismo e dedicação.

À Profa. Dra. Maria Cristina Borsatto, pela sua disponibilidade, simpatia e alegria, por ser um exemplo de dedicação, amabilidade, humildade e amor ao próximo.

À Profa. Dra. Aldevina Campos de Freitas, por ser um exemplo de amor e dedicação à profissão, pela paciência, disposição e humildade ao transmitir seus con hecimentos.

À Profa. Dra. Sada Assed, por ser um exemplo de determinação, dedicação e amor à profissão.

À Profa. Dra. Andiara De Rossi, pela sua disponibilidade, apoio e carinho, obrigada pelas palavas de apoio, no pouco tempo que tivemos jun tas.

Ao grande amigo que tive a chance de ter Fabrício, pela forma gentil e atenciosa agradeço pelos ensinamentos, pelas dúvidas compartilhadas e por estar sempre disponível para me ajudar

Às minhas inesquecíveis amigas e companheiras de casa: Ana Paula Zanetti Brochini, Maria Elisa Castela e Marcela Martin Del Campo Fiero pela ajuda, amizade, confiança, as risadas, experiências, conversas e momentos agradáveis, por ser parte muito importante da minha vida e ter sido as minhas imãs. Estare etemamente agradecida. Vocês são mais que apenas minhas amigas. Obrigada por me aguentarem... 
À minhas amigas: lana, Kitty, Lucila, Marina, Martinha, Maria, Raquel, Marcela e Aninha pelos cafés, as conversas, a confiança, motivação, apoio e a amizade durante todos estes anos. AMO TODAS VOCÊS...

À Faculdade de Odontologia de Ribeirão Preto da Universidade de São Paulo, na pessoa do atual diretor Prof. Dr, Osvaldo Luiz Bezzon e do ViceDiretor Prof. Dr. Valdemar Mallet da Rocha Barros.

À Coordenação do Curso De Pós-Graduação em Odontopediatria da Faculdade de Odontologia de Ribeirão Preto da Universidade de São Paulo, na pessoa da Coordenadora Profa. Dra. Léa Assed Bezera da Silva e do ViceCoordenador Prof. Dr. Paulo Nelson Filho.

Aos Professores do Departamento de Clínica Infantil, Odontologia Preventiva e Social da Faculdade de Odontologia de Ribeirão Preto da Universidade de São Paulo, Profa. Dra. Sada Assed, Prof. Dra. Léa Assed Bezerra da Silva, Profa. Dra. Aldevina Campos de Freitas, Prof. Dr. Paulo Nelson Filho, Profa. Dra. Alexandra Mussolino de Queiroz, Prof. Dr. Mário Roberto Leonardo, Profa. Dra. Raquel Assed Bezera da Silva, Profa. Dra. Kranya Victória Díaz Serrano, Profa. Dra. Maria Cristina Borsatto, Profa. Dra. Mírian Aiko Nakane Matsumoto, Prof. Dr. J osé Tarcísio Lima Ferreira, Prof. Dr. Adílson Thomazinho, Profa. Dr.a Maria Bemadete Sasso Stuani, Profa. Dra. Maria Conceição Pereira Saravia, Prof. Dr. Fábio Lourenço Romano e Profa. Dra. Andiara De Rossi.

Aos meus amigos e colegas da Pós-Graduação, Camila Scatena, Cíntia Guimarães de Almeida, Danielle Torres Azevedo, Luciane Almeida do Carmo, Marilia Pacífico Lucisano, Paula Dariana Femandes Ferreira, Rodrigo Alexandre Valério, Elaine Machado Pingueiro, Femanda Regina Ribeiro 
Santos, lliana Feraz Sabbatini, Késsia Suênia Fidelis de Mesquita, Ligia Maria Napolitano Gonçalves, Cristiane Tomaz Rocha, Fabrício Kitazono de Canvalho e Maya Amez, por tomar mais fácil e agradável este processo, pelos momentos compartilhados, a amizade e a convivên cia.

Aos funcionários do Departamento de Clínica Infantil, Odontología Preventiva e Social da Faculdade de Odontologia de Ribeirão Preto da Universidade de São Paulo, Micheli Cristina Leite Rovanholo, Filomeno Leli Placciti, Francisco Wanderley Garcia de Paula e Silva, Carolina Paes Torres Mantovani, Marco Antonio dos Santos, Nilza Letícia Magalhães, Fátima aparecida Rizoli, Fátima Aparecida Jacinto Daniel, Renata Aparecida Femandes e Matheus Morelli Zanela, pela sua ajuda, paciência e amizade.

Aos funcionários da Seção de Pós - Graduação da Faculdade de Odontologia de Ribeirão Preto da Universidade de São Paulo Isabel Cristina Galino Sola e Regiane Cristina Moi Sacilloto pela atenção e por estar sempre à disposição.

As funcionánias do Departamento de Odontologia Restauradora, da Faculdade de Odontologia de Ribeirão Preto da Universidade de São Paulo Juliana J anderoba Faraoni Romano e Patŕcia Marchi pela atenção e ajuda durante toda minha tese, vocês foram maravilhosas comigo, muito obrigada.

A todos os funcionários do Seniço de Radioterapia do Hospital das Clínicas da Faculdade de Medicina de Ribeirão Preto da Universidade de São Paulo, principalmente, Adélia e Leonardo, que me receberam com muita aten ção e me ajudaram durante toda minha tese, muito obrigada.

À CAPES (Coordenação de Aperfeiçoamento de Pessoal de Nível Superior), pela bolsa concedida. 


\section{Resumo}

Mellara, TS. Influência da irradiação com cobalto-60 nas propriedades mecânicas, químicas e morfológicas do esmalte e da dentina de dentes decíduos - estudo in vitro. Ribeirão Preto, 2010. 77 p. Dissertação [mestrado] - Faculdade de Odontologia de Ribeirão Preto, Universidade de São Paulo.

O objetivo do presente estudo foi avaliar, in vitro, os efeitos da irradiação com cobalto-60 (Co 60), nas propriedades do esmalte e da dentina de dentes decíduos por meio da: 1 - microdureza longitudinal; 2 morfologia em microscopia eletrônica de varredura (MEV); e 3 - composição química em espectroscopia de energia dispersiva de raios $X$ (EDX). No primeiro experimento foi avaliada a microdureza do esmalte e da dentina ( $n=12$ hemissecções vestibulares) em 3 profundidade (superficial, média e profunda), antes e a cada 10 Gy de irradiação, até uma dose cumulativa total de 60 Gy. No segundo experimento foi avaliada a morfologia do esmalte e da dentina por meio de MEV ( $n=8$ hemissecções), sendo 2 hemissecções vestibulares irradiadas com a dose cumulativa de $30 \mathrm{~Gy}, 2$ hemissecções vestibulares irradiadas com a dose cumulativa de $60 \mathrm{~Gy}$ e 4 hemissecções palatinas não irradiadas. No terceiro experimento, identificou-se os elementos químicos do esmalte e da dentina por meio de EDX ( $n=4$ hemissecções), utilizando-se as mesmas hemissecções previamente submetidas à MEV (com a dose cumulativa de $60 \mathrm{~Gy}$ de irradiação e nas hemissecções não irradiadas). No primeiro experimento a microdureza, antes e após, a irradiação, foi avaliada na mesma hemissecção dental (face vestibular). Já no segundo e terceiro experimentos, as hemissecções vestibulares foram submetidas à irradiação e as hemissecções palatinas do mesmo dente funcionaram como controle. Os dados foram analisados quanto à sua distribuição e submetidos à Análise de Variância a dois critérios. Para a diferenciação das médias, empregou-se o teste de Fisher. O nível de significância adotado foi de $5 \%$. A microdureza longitudinal no esmalte, como um todo, variou após as diferentes doses de irradiação, aumentando significantemente após a dose de $60 \mathrm{~Gy}(\mathrm{p}<0,05)$, com valores de 191,4 KH (controle); 184,7 KH (10 Gy); 184,6 KH (20 Gy); 192,9 KH (30 Gy); 198,2 KH (40 Gy); 204,1 KH (50 Gy) e 211,4 KH (60 Gy). Observou-se que no esmalte profundo foi encontrado o maior valor médio de microdureza $(206,7 \mathrm{KH})$, o qual foi estatisticamente diferente $(p<0,05)$ do valor médio das duas outras regiões avaliadas. Na microdureza longitudinal da dentina como um todo, após as diferentes doses de irradiação, observou-se diferença estatisticamente significante entre os valores de microdureza da dentina não irradiada $(28,9 \mathrm{KH}) \mathrm{com}$ relação à dentina irradiada com doses de $10 \mathrm{~Gy}(23,8 \mathrm{KH}), 20 \mathrm{~Gy}(25,6 \mathrm{KH}), 30 \mathrm{~Gy}(24,8 \mathrm{KH})$ e $40 \mathrm{~Gy}$ $(25,7 \mathrm{KH})(\mathrm{p}<0,05)$. As doses $50 \mathrm{~Gy}$ e $60 \mathrm{~Gy}$ apresentaram o mesmo valor médio de microdureza $(26,7$ $\mathrm{KH})$ e diferente da dose de $10 \mathrm{~Gy}$ de irradiação $(p<0,05)$. Com $60 \mathrm{~Gy}$ não houve diferença estatisticamente significante quando comparado à dentina não irradiada $(p>0,05)$. Observou-se que na dentina média foi encontrado o maior valor médio de microdureza $(29,9 \mathrm{KH})$, o qual foi estatisticamente diferente $(p<0,05)$ das outras regiões avaliadas. Na análise morfológica do esmalte observou-se que os grupos irradiados com dose de 30 Gy e 60 Gy mostraram maiores alteração da superfície do esmalte, em comparação ao esmalte não irradiado para todas as regiões analisadas, o mesmo ocorrendo na dentina. $\mathrm{Na}$ análise química do esmalte e da dentina irradiados, quando comparados aos espécimes não irradiados, observou-se redução de oxigênio (O) e aumento de cálcio (Ca). Conclui-se que a irradiação de dentes decíduos com Co-60 influenciou a microdureza longitudinal do esmalte e da dentina, dependendo da dose e da área irradiada. No esmalte como um todo, a microdureza aumentou com a dose cumulativa de $60 \mathrm{~Gy}$, independente da área analisada. Na dentina, não houve alteração dos valores de microdureza após irradiação, independente da área analisada. Com relação à morfologia, foi observada desorganização do esmalte e da dentina, que passaram a apresentar uma superfície amorfa com aumento das doses de irradiação, com maior dificuldade de identificação dos prismas de esmalte e túbulos dentinários, respectivamente. Quimicamente observou-se redução na porcentagem de oxigênio e aumento na porcentagem de cálcio no esmalte e na dentina irradiados.

Palavras- chave: Radioterapia, cobalto 60, cárie de radiação, microdureza, dentes decíduos, composição química, morfologia 


\section{ABSTRACT}

Mellara, TS. Influence of cobalto-60 irradiation on the mechanical, chemical and morphological properties of enamel and dentin of primary teeth - an in vitro study. Ribeirão Preto, 2010. 77 p. Dissertação [mestrado] - Faculdade de Odontologia de Ribeirão Preto, Universidade de São Paulo.

The aim of this study was to evaluate, in vitro, the effects of cobalto-60 (Co 60) irradiation on the properties of enamel and dentin of primary teeth by analysis of: 1 - longitudinal microhardness; 2 morphology by scanning electron microscopy (SEM); and 3 -chemical composition by energy-dispersive $X$-ray spectroscopy (EDX). In the first experiment, enamel and dentin microhardness ( $n=12$ buccal hemisections) was evaluated at 3 depths (superficial, meddle and deep), before and at each 10 Gy irradiation, up to a total cumulative dose of $60 \mathrm{~Gy}$. In the second experiment, enamel and dentin morphology was evaluated by SEM ( $n=8$ hemi-sections), being 2 buccal hemi-sections irradiated with a cumulative dose of $30 \mathrm{~Gy}, 2$ buccal hemi-sections irradiated with a cumulative dose of $60 \mathrm{~Gy}$ and 4 non-irradiated palatal hemi-sections. In the third experiment, the chemical elements in enamel and dentin were identified by EDX ( $n=4$ hemi-sections), using the same hemi-sections previously subjected to SEM analysis (irradiated with a cumulative dose of $60 \mathrm{~Gy}$ and non-irradiated). In the first experiment, microhardness was evaluated before and after irradiation in the same dental hemi-section (buccal face). In the second and third experiments, the buccal hemi-sections were irradiated and the palatal hemi-sections of the same tooth served as control. After analysis of distribution, data were subjected to two-way analysis of variance and Fisher's exact test was used for differentiation of means. A significance level of $5 \%$ was adopted. Overall, longitudinal microhardness of enamel varied after the different irradiation doses, increasing significantly after the dose of $60 \mathrm{~Gy}(\mathrm{p}<0.05)$, with values of $191.4 \mathrm{KH}$ (control); $184.7 \mathrm{KH}(10$ Gy); 184.6 KH (20 Gy); 192.9 KH (30 Gy); 198.2 KH (40 Gy); 204.1 KH (50 Gy) and 211.4 KH (60 Gy). Deep enamel presented the highest mean value of microhardness $(206.7 \mathrm{KH})$, which was significantly different $(p<0.05)$ from the mean values of the other evaluated regions. Overall, after the different irradiation doses, there was statistically significant difference between the longitudinal microhardness values of non-irradiated dentin $(28.9 \mathrm{KH})$ compared with dentin irradiated with doses of $10 \mathrm{~Gy}(23.8 \mathrm{KH})$, $20 \mathrm{~Gy}(25.6 \mathrm{KH}), 30 \mathrm{~Gy}(24.8 \mathrm{KH})$ and $40 \mathrm{~Gy}(25.7 \mathrm{KH})(\mathrm{p}<0.05)$. The doses of $50 \mathrm{~Gy}$ and $60 \mathrm{~Gy}$ presented the same mean value of microhardness $(26.7 \mathrm{KH})$ and differed from the dose of $10 \mathrm{~Gy}$ irradiation $(p<0.05)$. There was no statistically significant difference for irradiation with $60 \mathrm{~Gy}$ compared with non-irradiated dentin $(p>0.05)$. The highest mean value of microhardness was obtained in the middle dentin $(29.9 \mathrm{KH})$, which was significantly different $(p<0.05)$ from the other analyzed regions. The morphological analysis of enamel and dentin revealed that the groups irradiated with doses of $30 \mathrm{~Gy}$ and 60 Gy presented greater surface alterations compared with non-irradiated specimens at all analyzed regions. The chemical analysis of irradiated enamel and dentin compared with non-irradiated specimens revealed a decrease of oxygen and an increase of calcium. In conclusion, irradiation of primary teeth with Co-60 influenced the longitudinal microhardness of enamel and dentin, according to the dose and irradiated region. In enamel as a whole, microhardness increased with the cumulative dose of $60 \mathrm{~Gy}$, regardless of the analyzed region. In dentin, there was no change in the microhardness mean values after irradiation, regardless of the analyzed region. The analysis of morphology revealed that, the increase of the irradiation dose resulted in enamel and dentin disorganization, which presented an amorphous surface with difficulty in identifying enamel prisms and dentin tubules, respectively. The chemical analysis revealed a decrease in the percentage of oxygen and an increase in the percentage of calcium in irradiated enamel and dentin.

Key words: Radiotherapy, 60 cobalt, radiation caries, microhardness, primary teeth, chemical composition, morphology. 


\section{SUMÁRIO}

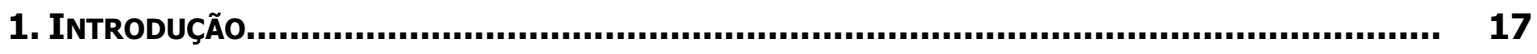

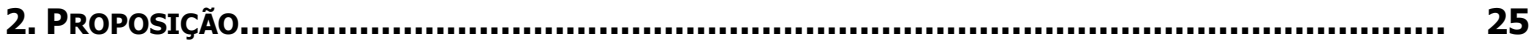

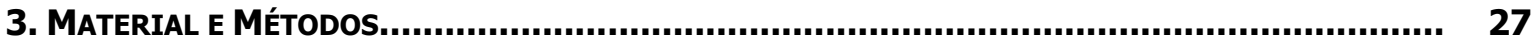

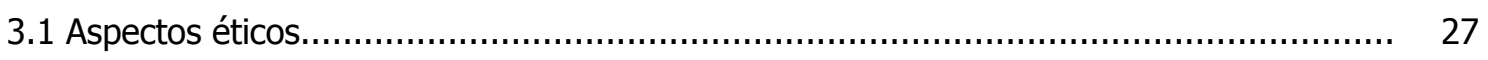

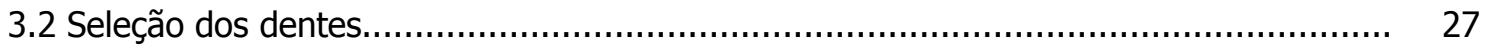

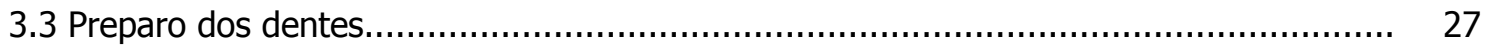

3.4 Delineamento experimental.............................................................. 31

3.5 Irradiação com Co-60.................................................................................. 31

3.6 Avaliação da microdureza longitudinal de esmalte e dentina de dentes................. 32

3.6.1 Pré-irradiação com Co-60.................................................................. 32

3.6.2 Pós-irradiação com Co-60..................................................................... 33

3.7 Avaliação em microscopia eletrônica de varredura (MEV)..................................... 37

3.8 Avaliação por espectroscopia de energia dispersiva de raios X (EDX).................. 41

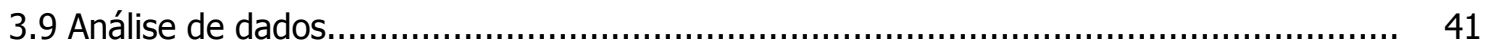

4. ReSULTADOS......................................................................................................... 43

4.1 Avaliação da microdureza longitudinal........................................................... 43

4.1.1 Esmalte de dentes decíduos................................................................. 43

4.1.2 Dentina de dentes decíduos ...................................................................... 46

4.2 Avaliação em microscopia eletrônica de varredura (MEV) ..................................... 49

4.2.1 Esmalte de dentes decíduos.................................................................... 49

4.2.2 Dentina de dentes decíduos..................................................................... 53

4.3 Avaliação por espectroscopia de energia dispersiva de raios X (EDX)................... 57

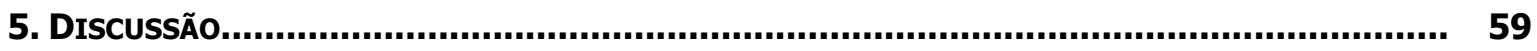

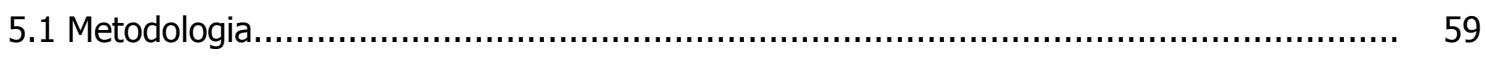

5.2 Alterações no esmalte de dentes decíduos.............................................................. 61

5.3 Alterações na dentina de dentes decíduos............................................................. 63

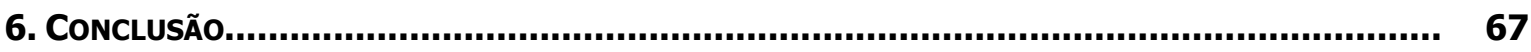

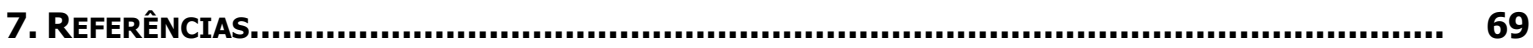

ANEXo 


\section{INTRODUÇÃO}

Denomina-se câncer como doenças que tem em comum o crescimento desordenado de células que invadem tecidos e órgãos, podendo sofrer metástase para outras regiões (INCA, 2009). A cada ano, aproximadamente, 500.000 novos casos de câncer de cabeça e pescoço são diagnosticados ao redor do mundo (Shibuya et al., 2002). Estimativa do Instituto Nacional do Câncer (INCA), órgão do Ministério da Saúde do Brasil voltado a ações nacionais integradas para o controle e prevenção da neoplasia, revela que no ano de 2010 ocorrerão no Brasil 375.420 novos casos de câncer, excetuando-se os tumores de pele não-melanoma. Como o percentual mediano dos tumores pediátricos observados nos brasileiros encontra-se próximo de 2,5\%, depreende-se que ocorrerão cerca de 9.386 novos casos de câncer em crianças e adolescentes até os 18 anos, no ano de 2010 (INCA, 2009).

Embora a ocorrência de câncer de cabeça e pescoço em crianças seja mais rara que em adultos, ocorrem casos de tumores do sistema nervoso central, neuroblastoma, retinoblatoma, algumas neoplasias de células germinativas, tumores ósseos e sarcomas de partes moles, dentre outros (INCA, 2009).

A radioterapia, uma modalidade de tratamento que utiliza radiação ionizante como agente terapêutico (Novaes, 1998; Chaachouay et al., 2011), é amplamente utilizada para o tratamento do câncer de cabeça e pescoço, como terapia primária, coadjuvante ao tratamento cirúrgico. Este tratamento é efetuado em conjunção simultaneamente com a quimioterapia ou como tratamento paliativo em tumores de cabeça e pescoço em estágios finais e inoperáveis (Adelstein, 2003; Soares et al., 2010; Soares et al., 2011).

Embora a radioterapia possa elevar as porcentagens de cura, pacientes irradiados na região de cabeça e pescoço são suscetíveis a efeitos secundários na cavidade bucal, que incluem mucosite, xerostomia, perda de paladar, trismo, perda progressiva do ligamento periodontal, alterações microvasculares, necrose de tecidos moles, osteoradionecrose e cárie dental (Ramirez-amador et al., 1997; Sulaiman et al., 2003; Vissink et al., 2003; Jham e da Silva Freire, 2006). A incidência e a prevalência precisa das sequelas e dos efeitos colaterais induzidos pela radioterapia são difíceis de serem obtidos, com valores variando de 13 a $89 \%$ (Ohrn et al., 2001).

A cárie dental relacionada à irradiação, ou "cárie de radiação", é uma doença complexa e destrutiva, de origem multifatorial, que atinge pacientes submetidos à radioterapia de cabeça e pescoço (Vissink et al., 2003; Kielbassa et al., 2006; Silva et al., 2009a; b) e prejudica a qualidade de vida desses pacientes (Silva et al., 2009a) sendo, 
segundo Al-Nawas et al. (2000), a principal complicação de pacientes com câncer de cabeça e pescoço. Evidências científicas sugerem que o risco para o desenvolvimento da cárie de radiação estará presente por toda a vida dos pacientes, após a radioterapia (Kielbassa et al., 2006).

De acordo com diferentes estudos (Jansma et al., 1990; Kielbassa, 2000; Kielbassa et al., 2000; Vissink et al., 2003; Kielbassa et al., 2006; Silva et al., 2009a; b) os efeitos indiretos da irradiação, que incluem alterações na qualidade e na quantidade da saliva, dificuldade em realizar uma higiene bucal adequada em função do desenvolvimento de mucosites e da rigidez muscular, aumento do consumo de alimentos cariogênicos e alterações na microbiota bucal, são os principais agentes causais da cárie de radiação, a qual ocasiona a severa destruição do esmalte e da dentina de dentes de pacientes submetidos à radioterapia de cabeça e pescoço.

O efeito da irradiação terapêutica (dose de 2 Gy, duas vezes ao dia, até o total de 72 Gy) na permeabilidade do esmalte dental bovino, por meio de difusão de radioisótopo, foi avaliado por Jansma et al. (1990), os quais não verificaram alterações na permeabilidade do esmalte dos dentes irradiados.

Kielbassa et al. (1999) avaliaram a correlação entre os resultados da microdureza e microrradiografias tranversais de lesões de cárie induzidas, in situ, em espécimes de esmalte de dentes permanentes humano irradiado e não irradiado, com doses de 60 Gy (com um total de 4 doses- 15 Gy/dia, 4 doses/semana). Os espécimes foram acoplados em dispositivos intrabucais, que continham do mesmo lado um espécime irradiado e um não irradiado, os quais foram utilizados pelos pacientes por 6 semanas. Apenas um dos lados do dispositivo foi escovado, diariamente, sendo o dentifrício não fluoretado. A perda mineral foi calculada com auxílio de um software nos mesmos locais onde foi avaliada a microdureza. Os autores verificaram que nem a microdureza, e nem as microrradiografias transversais demonstraram diferença significante com relação às lesões de cárie dos espécimes irradiados e não irradiados, e concluíram que o esmalte irradiado não é mais susceptível à cárie dental que o não irradiado, se padrões adequados de higiene bucal forem adotados.

Em 2000, Kielbassa et al., por meio de estudos microscópicos e microrradiográficos, avaliaram, in situ, o início da desmineralização do esmalte de dentes permanentes humano irradiado e não irradiado, com doses de 60 Gy (2 Gy/dia, 5 dias/semana). Os espécimes foram acoplados em dispositivos intrabucais, que continham do mesmo lado um espécime irradiado e um não irradiado, os quais foram utilizados por 6 semanas. Apenas um dos lados do dispositivo foi escovado, diariamente, sendo o dentifrício 
não fluoretado. Os resultados demonstraram ausência de diferenças microscópicas e microrradiográficas entre as lesões de esmalte dos espécimes irradiados e não irradiados. Os autores concluíram que os efeitos diretos da irradiação no esmalte dental não são responsáveis pelo início da desmineralização sob condições clínicas, e que o início das lesões de cárie em esmalte irradiado pode ser controlado por técnicas de higiene bucal adequadas.

Ainda em 2000, Kielbassa publicou um estudo no qual avaliou, in situ, por meio de estudos microscópicos e microrradiográficos, a desmineralização inicial da dentina de dentes permanentes humanos irradiados e não irradiada, com doses de 60 Gy (2 Gy/dia, 5 dias/semana). Os espécimes foram acloplados em dispositivos intrabucais, que continham do mesmo lado um espécime irradiado e um não irradiado, os quais foram utilizados por 5 semanas. Apenas um dos lados do dispositivo foi escovado, diariamente, sendo o dentifrício não fluoretado. Os resultados demonstraram ausência de diferenças significantes com relação à perda mineral e profundidade da lesão de cárie entre os espécimes irradiados e não irradiados. Essa diferença ocorreu apenas entre os espécimes escovados e os não escovados. Portanto, a dentina de dentes irradiados não se tornou mais susceptível à cárie dental que a de dentes não irradiados, quando submetida à adequada higiene bucal.

Os padrões de desmineralização das lesões de cárie nos pacientes adultos irradiados foi avaliado por Silva et al. (2009a), os quais verificaram que a cárie cervical e incisal em dentes permanentes foram largamente detectadas. Adicionalmente, descoloração marrom difusa da superfície do esmalte foi frequentemente observada e a microscopia de luz polarizada sugeriu que essas áreas eram referentes a lesões de cárie incipientes. Houve, ainda, evidências de função odontoblástica normal em detrimento da presença de dentina reacional e deposição de dentina intratubular. Os autores concluíram que a cárie dental relacionada à irradiação apresenta a mesma morfologia e padrão que a cárie dental não relacionada à irradiação, com presença de dentina mineralizada, zona translucente, dentina com tratos mortos, dentina reacional e deposição de dentina intratubular.

Por outro lado, outros estudos em dentes permanentes e em dentes bovinos (Jervoe, 1970; Markitziu et al., 1986; Jansma et al. 1988; Pioch et al., 1992; Kielbassa et al., 1997; Grötz et al., 1997; 1998; Al-Nawas et al., 2000; Springer et al., 2005; Açil et al., 2007; Soares et al., 2010; Soares et al., 2011) demonstram que a irradiação ocasiona efeitos diretos sobre a estrutura dental, sendo este efeito parte da patogênese da cárie de radiação.

O estudo de Jervoe, de 1970, demonstrou por meio de difração de raios X, que a irradiação de dentes permanentes humanos com um M-rad, tanto em doses simples como cumulativas, bem como a irradiação in situ com $12000 \mathrm{R}$ induziram alterações na estrutura cristalina do esmalte e da dentina. 
Markitziu et al. (1986) avaliaram, in vitro, os efeitos da irradiação com Co-60 na solubilidade e dureza do esmalte e dentina de dentes permanentes humanos pré-tratados ou não com flúor em três diferentes grupos: não irradiado; na dose de 3500 rads e 7000 rads. A exposição à irradiação não afetou a solubilidade do esmalte dos dentes não tratados ou pré-tratados com flúor. Entretanto, a solubilidade da dentina dos dentes não tratados com flúor diminuiu, no grupo submetido à irradiação. Com relação à microdureza, não foram observadas alterações nos espécimes de esmalte irradiados, com ou sem pré-tratamento com flúor. No entanto, a exposição à irradiação diminuiu a dureza da dentina, quando não ocorreu o pré-tratamento com flúor.

Jansma et al. (1988) avaliaram o efeito da irradiação (dose de 72 Gy, 2 Gy, duas vezes ao dia, durante o período de 18 dias) no esmalte de dentes bovinos desmineralizados, in vitro. Os autores observaram que as medidas de microdureza após a desmineralização mostraram diferenças significantes entre o esmalte irradiado e não irradiado. Microrradiografias quantitativas mostraram que tanto a perda mineral quanto a profundidade da lesão foram significantemente menores para os espécimes irradiados, em comparação aos não irradiados, demonstrando que a irradiação diminuiu a solubilidade ácida do esmalte.

Significante redução na estabilidade da região da junção amelodentinária de incisivos bovinos após irradiação (dose de 70 Gy) foi observada por Pioch et al. (1992), por meio de testes de resistência ao cisalhamento e observação por meio de microscopia eletrônica de varredura. Os autores concluíram que a irradiação ocasionou alterações nas propriedades biofísicas dos dentes e que a redução na estabilidade da junção amelodentinária justifica as características clínicas frequentemente observadas em pacientes após a irradiação, que incluem a perda de esmalte resultando na exposição da dentina na região cervical ou vestibular de incisivos, bem como na superfície oclusal de molares.

Kielbassa et al. (1997) realizaram um estudo in vitro, com o objetivo de avaliar os efeitos da irradiação, com doses de 60 Gy (2 Gy/dia, 5 dias/semana), na microdureza da dentina de dentes bovinos, em presença ou ausência de flúor. Os autores concluíram que a dentina foi severamente afetada pela irradiação e que a fluoretação com géis ácidos diminuiu a microdureza da superfície dentinária e não preveniu seu amolecimento devido à irradiação. Segundo esses autores esta poderia ser uma explicação para a formação de "gaps" na junção amelodentinária, perda de esmalte dental e lesões de cárie cervicais, que acometem indivíduos submetidos à radioterapia de cabeça e pescoço.

Ainda em 1997, Grötz et al. sugeriram em seu estudo que as alterações na junção amelodentinária de dentes submetidos à irradiação ocorrem em virtude da atrofia dos 
processos odontoblásticos. A obliteração dos túbulos dentinários, precedida pela degeneração dos processos odontoblásticos seria, obviamente, resultado do dano celular causado pela irradiação, a qual ocasionaria impedimento da vascularização e do metabolismo, particularmente na área das terminações dos processos odontoblásticos.

Em 1998, Grötz et al. avaliaram, os efeitos diretos da radioterapia sobre o esmalte dental. Espécimes de esmalte após altas doses de irradiação in vitro (500-2500 Gy), espécimes de esmalte submetidos à irradiação in situ de 60 Gy e dentes extraídos de pacientes em virtude de complicações após tratamento radioterápico com 36 ou 60 Gy, permitiram verificar que a desmineralização em áreas subsuperficiais de dentes de pacientes submetidos à radioterapia é caracterizada pela perda total da estrutura prismática. Os autores concluíram que ocorrem diferenças micromorfométricas significantes no processo de desmineralização do esmalte de dentes submetidos à irradiação, o qual se torna menos resistente aos desafios ácidos.

Springer et al. (2005) verificaram, por meio da mensuração das proteínas (hidroxilisilpiridinolina e lisipiridinolina), as quais são duas reações cruzadas não reduzidas no colágeno maduro que aumentam quando ocorre a destruição do colágeno por irradiação (6.3 Gy/dia, por 5 dias), que a irradiação causou danos diretos sobre o colágeno do tecido pulpar. Entretanto, não observaram alterações mensuráveis do componente colágeno nos tecidos dentais mineralizados, e creditaram esse fato à concentração relativamente baixa destas proteínas no esmalte e na dentina.

Açil et al. (2007) avaliaram, in vitro, o dano direto e imediato ao colágeno, como consequência direta da irradiação com dose de $60 \mathrm{~Gy}$, em tecido ósseo, periósteo e pele de mandíbulas de porcos, em comparação a mandíbulas não irradiadas. Os tipos de colágeno foram caracterizados por eletroforese em gel de poliacrilamida (SDS-PAGE) e a maturação das fibras, determinada pela quantidade de ligações cruzadas hidroxilisilpiridinolina (HP) e lisilpiridinolina (LP), foi avaliada por meio de cromatografia líquida de alta performance (HPLC). A mensuração da quantidade de hidroxiprolina (Hyp) foi utilizada para determinar a razão entre a quantidade de fragmentos de colágeno nas amostras irradiadas comparado às amostras não irradiadas. A concentração de HP, LP e Hyp no grupo irradiado encontrou-se marcadamente aumentada. SDS-PAGE demonstrou a presença de colágeno I e IV no osso não irradiado, I e III na pele não irradiada, e I no periósteo não irradiado. Nas amostras irradiadas, bandas difusas demonstraram a fragmentação da molécula de colágeno. O aumento da concentração de HP, LP e Hyp no ultrafiltrado indicaram o aumento da concentração de colágeno desnaturado, demonstrando o dano direto e imediato da irradiação sobre o colágeno. 
Soares et al. (2010) estudaram o efeito da irradiação gama sobre a resistência à tração do esmalte e de dentina em dentes permanentes, em relação à orientação dos prismas, dos túbulos dentinários e localização. Quarenta terceiros molares humanos permanentes foram usados, metade dos quais foram submetidos a 60 Gy de irradiação gama, sendo 2 Gy/dia e avaliados por meio de teste de microtração. Os resultados demonstraram que o tratamento com irradiação diminuiu significantemente a resistência à tração da dentina radicular e coronária do esmalte, a despeito da orientação dos túbulos e dos prismas. Com ou sem irradiação o esmalte foi significantemente mais forte quando testado paralelamente à sua orientação prismática. A dentina coronária e radicular, não irradiadas, apresentaram resistência à tração significantemente maior quando testadas perpendicularmente a orientação dos prismas. Entretanto, quando os dentes foram irradiados não houve influência da orientação dos túbulos, demonstrando que a irradiação é mais danosa aos componentes orgânicos que aos inorgânicos.

Em 2011, Soares et al. realizaram um estudo, in vitro, com o objetivo de avaliar se diferentes protocolos de enxaguatórios bucais eram capazes de prevenir os danos da radioterapia com irradiação gama, com relação à resistência à tração do esmalte e da dentina. Cento e vinte dentes foram divididos em dois grupos: irradiados (submetidos a 60 Gy de irradiação gama, em incrementos diários de 2 Gy) e não-irradiados. Estes foram subdivididos em dois protocolos, utilizando soluções para bochechos três vezes ao dia de clorexidina a $0,12 \%$ ou de fluoreto de sódio a 0,05\%, e um grupo controle. Os espécimes foram avaliados por teste de microtração. Os resultados indicaram que a irradiação gama reduziu significantemente a resistência à tração do esmalte e da dentina coronária e radicular. As alterações macromoleculares foram sugeridas na dentina. Alterações estruturais em ambos os substratos foram detectados por microscopia eletrônica de varredura. Bochechos com clorexidina a 0,12 \% preveniram parcialmente os danos às propriedades mecânicas da dentina coronária irradiada, enquanto que o fluoreto de sódio a 0,05 \% apresentou similaridade no teste de resistência à tração, tanto no esmalte irradiado quanto não irradiado.

Apesar dos vários estudos descritos acima, o mecanismo envolvido no desenvolvimento da cárie dental pós-radioterapia na região de cabeça e pescoço continua controverso (Grötz et al., 1998; Al-Nawas et al., 2000; Craddock, 2006; Craddock, 2008). Ora esse mecanismo é atribuído aos efeitos indiretos da radioterapia, que levam a alterações salivares, dificuldades de higiene bucal, consumo maior de alimentos cariogênicos e alterações da microbiota bucal; e ora é atribuído aos efeitos diretos da irradiação que ocasionam alterações na estrutura e na composição química do esmalte e da dentina. Esses 
efeitos são ainda mais desconhecidos na dentição decídua, uma vez que todos os trabalhos de pesquisa previamente publicados foram efetuados em dentes de bovinos ou em dentes permanentes de humanos. 


\section{PROPOSIÇÃO}

O objetivo do presente estudo foi avaliar, in vitro, os efeitos da irradiação com cobalto-60 (Co-60), nas propriedades do esmalte e da dentina de dentes decíduos por meio da:

- Microdureza longitudinal do esmalte e da dentina;

- Morfologia do esmalte e da dentina por meio de microscopia eletrônica de varredura (MEV); e

- Composição química do esmalte e da dentina por meio da espectroscopia de energia dispersiva de raios $X(E D X)$. 


\section{MATERIAL e MÉTOdO}

\subsection{ASPECTOS ÉTICOS}

Inicialmente, o projeto de pesquisa foi submetido à apreciação pelo Comitê de Ética em Pesquisa da Faculdade de Odontologia de Ribeirão Preto da Universidade de São Paulo (processo número 2010.1.1512.58.9), tendo sido aprovado (Anexo).

\subsection{SELEÇÃO DOS DENTES}

A amostra foi constituída de 16 molares decíduos de humanos, superiores e inferiores, recém-extraídos ou recém-esfoliados e hígidos, obtidos junto ao Banco de Dentes da Faculdade de Odontologia de Ribeirão Preto da Universidade de São Paulo, armazenados em água destilada, à temperatura de $4{ }^{\circ} \mathrm{C}$.

Os dentes foram submetidos à profilaxia com pasta de pedra-pomes e água, com o auxílio de uma escova tipo Robinson montada em micromotor, em baixa rotação. A seguir, com o auxílio de uma sonda exploradora e de um estereomicroscópio (Nikon Inc. Instrument Group, Melville, New York, United States of America) com aumento de 10x, foi realizado o exame tátil e visual, sendo selecionados apenas os dentes que não apresentaram trincas, fraturas, lesões de cárie ou anomalias de estrutura.

Após serem selecionados, os dentes permaneceram armazenados em solução de timol a 0,1\% supersaturada durante 1 semana. Sendo a seguir lavados em água por 24 horas. Após esse período os dentes foram colocados em recipientes contendo água destilada e congelados a $-20^{\circ} \mathrm{C}$, até o início do experimento.

\subsection{PREPARO DOS DENTES}

Os dentes previamente selecionados que ainda apresentavam raízes, em decorrência do processo incompleto de rizólise, foram inicialmente seccionados $1 \mathrm{~mm}$ abaixo da junção amelocementária, com disco diamantado adaptado em máquina de corte (Miniton, Struers A/S, Copenhagen, Dinamarca), sob refrigeração, para remoção do remanescente radicular.

Cada dente foi então seccionado no sentido mésio/distal, obtendo-se duas metades, sendo uma correspondente à hemissecção vestibular e outra à hemissecção lingual ou palatina, num total de 32 hemissecções. As superfícies seccionadas foram lixadas com 
lixas d'água (Norton S/A, Curitiba, Brasil) de granulação \# 600 e \# 1200 e polidas com feltro embebido em alumina (Arotec S/A, Cotia, Brasil) de 0,3 $\mu \mathrm{m}$ e 0,05 $\mu \mathrm{m}$. Todo o procedimento de polimento superficial foi realizado em politriz (DP-9U2, Panambra/Strues, A/S, Copenhagen, Denmark), sob refrigeração (Fluxograma 1). 


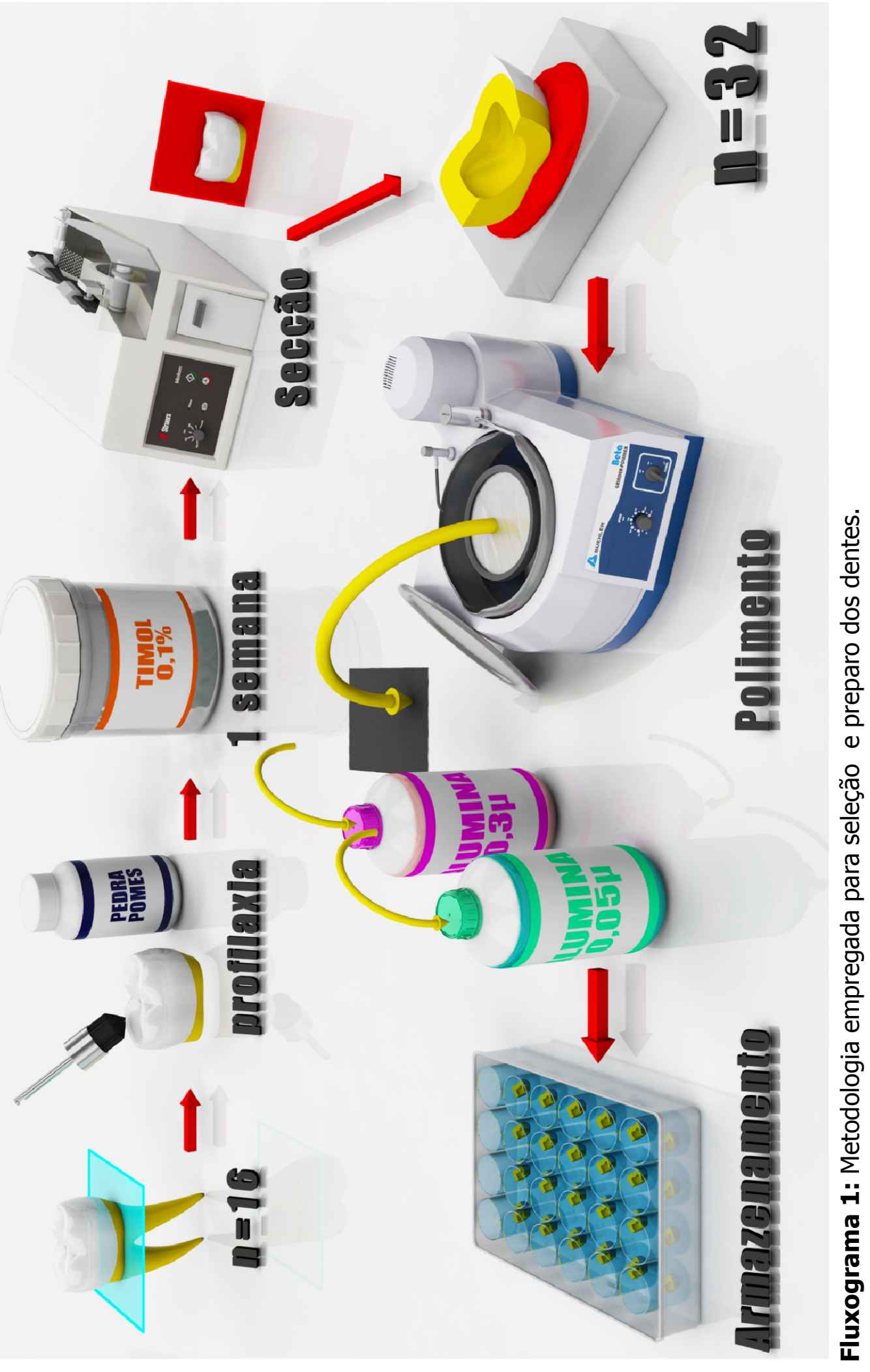




\subsection{DELINEAMENTO EXPERIMENTAL}

As 32 hemissecções dentais, vestibulares e palatinas correspondentes, foram submetidas a três experimentos sendo, para tal finalidade, subdivididos randomicamente em três grupos, pelo método da loteria (Leedy, 1997). No primeiro experimento foi avaliada a microdureza do esmalte e da dentina ( $n=12$ hemissecções vestibulares), antes e a cada 10 Gy de irradiação com Co-60, até uma dose cumulativa total de 60 Gy. No segundo experimento foi avaliada a morfologia do esmalte e da dentina por meio de microscopia eletrônica de varredura ( $\mathrm{n}=8$ hemissecções), sendo 2 hemissecções vestibulares irradiadas com a dose cumulativa de 30 Gy, 2 hemissecções vestibulares irradiadas com a dose cumulativa de 60 Gy e 4 hemissecções palatinas (não irradiadas). No terceiro experimento, identificaram-se os elementos químicos do esmalte e da dentina por meio de espectroscopia de energia dispersiva de raios $X$ (EDX) ( $n=4$ hemissecções), utilizando-se as mesmas hemissecções previamente submetidas à microscopia eletrônica de varredura na dose cumulativa de 60 Gy de irradiação com Co-60 e nas hemissecções não irradiadas. No primeiro experimento a microdureza, antes e após, a irradiação, foi avaliada na mesma hemissecção dental (face vestibular). Já no segundo e terceiro experimentos, as hemissecções vestibulares foram submetidas à irradiação e as hemissecções palatinas do mesmo dente funcionaram como controle.

\subsection{IRRADIAÇÃO COM Co-60}

Para esse procedimento as hemissecções dentais (face vestibular) a serem irradiadas foram colocadas em placas de acrílico para cultura de células de 24 poços (Cellstar®, ref. 657160, Greiner bio-one GmbH, Frickenhausen, Germany), possibilitando que todas recebessem a mesma irradiação direta por unidade de área. Com o intuito de manter as hemissecções dentais em um ambiente úmido, simulando as características da cavidade bucal, durante a irradiação, cada poço foi preenchido com $10 \mathrm{ml}$ de saliva artificial, pH = 7,0 (Faculdade de Ciências Farmacêuticas de Ribeirão Preto - Universidade de São Paulo, Ribeirão Preto, Brasil), recobrindo totalmente as hemissecções.

A seguir as hemissecções dentais foram expostas à irradiação com Co-60 em aparelho de telecolterapia (Siemens modelo Gammatron 580, Munich, Germany), no Serviço de Radioterapia do Hospital das Clínicas da Faculdade de Medicina de Ribeirão PretoUniversidade de São Paulo, com distância da fonte de $80 \mathrm{~cm}$, com dose de $1 \mathrm{~Gy} / \mathrm{min}$. As hemissecções dentais foram irradiadas com fração de dose de $2 \mathrm{~Gy}, 5$ dias consecutivos, até 
atingirem a dose total de $60 \mathrm{~Gy}$, com um total de 30 ciclos, durante 6 semanas (Kielbassa et al., 2000; Açil et al., 2007; Bulucu et al., 2009; Aggarwal, 2009; Soares et al., 2010, Soares et al., 2011).

Entre os ciclos de irradiação as hemissecções foram mantidas em saliva artificial, renovada diariamente, em estufa a $37{ }^{\circ} \mathrm{C}$ (Olidef $\mathrm{CZ}$, Indústria e Comércio de Aparelhos Hospitalares Ltda., Ribeirão Preto, Brasil).

\subsection{AVALIAÇÃO DA MICRODUREZA LONGITUDINAL DE ESMALTE E DA DENTINA DE DENTES DECÍDUOS}

\subsubsection{PRÉ-IRRADIAÇÃO COM Co-60}

Inicialmente, a microdureza longitudinal inicial do esmalte e da dentina de dentes decíduos, foi avaliada nas hemissecções vestibulares de 12 dentes, antes destas serem submetidas à irradiação. Para a análise da microdureza, as hemissecções foram adaptadas a uma base de acrílico (lâmina de plexiglass) com auxílio de um paralelômetro (ElQuip, São Carlos, Brasil), e niveladas de forma a deixar a região mais planificada da hemissecção paralela à base. Em seguida, as hemissecções foram fixadas e estabilizadas com cera para escultura (Kota Ind. e Com. Ltda, São Paulo, Brasil), aquecida com gotejador elétrico (Guelfi Equipamentos, Ribeirão Preto, Brasil).

A microdureza longitudinal foi avaliada em um microdurômetro (Shimadzu Micro Hardness Tester HMV-2000- Corporation, Kyoto, Japan), com auxílio de um penetrador de diamante para dureza Knoop (KH), aplicando uma carga de $25 \mathrm{gf}$ com duração de 10 segundos no esmalte e uma carga de 10 gf com duração de 15 segundos na dentina, de maneira que a ponta do penetrador permanecesse paralela à superfície do esmalte e da dentina.

No esmalte, foram realizadas indentações em três regiões distintas: a primeira a $50 \mu \mathrm{m}$ da borda externa (esmalte superficial), a segunda na metade da espessura do esmalte (esmalte médio) e a terceira a $50 \mu \mathrm{m}$ da junção amelodentinária (esmalte profundo).

Similarmente ao esmalte, na dentina foram selecionadas três regiões para a realização das indentações, a primeira região a $50 \mu \mathrm{m}$ da junção amelodentinária (dentina superficial), a segunda na metade da espessura da dentina (dentina média) e a terceira a 50 um da câmara pulpar (dentina profunda). 
Para cada região selecionada foram realizadas três medidas de microdureza, sendo a distância entre elas de $100 \mu \mathrm{m}$ no esmalte e de $150 \mu \mathrm{m}$ na dentina. A média dessas medidas foi utilizada para a análise dos dados.

Uma vez avaliada a microdureza inicial das 12 hemissecções vestibulares dos dentes, estes foram submetidos à irradiação com Co-60.

\subsubsection{PÓS-IRRADIAÇÃO COM Co-60}

As medidas de microdureza após a irradiação com Co-60, ou seja, microdureza longitudinal final do esmalte e da dentina, foram realizadas nas mesmas 12 hemissecções dentais vestibulares a cada 5 ciclos de irradiação, que equivale a uma dose de 10 Gy e a um período de tempo de 5 dias consecutivos. A última medida de microdureza foi realizada após totalizar 30 ciclos de irradiação, que equivale a uma dose de 60 Gy, e a um período de tempo de 30 dias (Tabela 1).

Tabela 1 - Número de ciclos de irradiação, períodos de tempo e doses totais empregadas, nas 12 hemissecções dentais avaliadas, com relação à microdureza longitudinal

\begin{tabular}{ccc}
\hline $\begin{array}{c}\text { Número de ciclos de } \\
\text { irradiação }\end{array}$ & $\begin{array}{c}\text { Período de tempo } \\
\text { (dias) }\end{array}$ & $\begin{array}{c}\text { Dose total } \\
\text { (2 Gy por ciclo) }\end{array}$ \\
\hline 5 & 5 & $10 \mathrm{~Gy}$ \\
10 & 10 & $20 \mathrm{~Gy}$ \\
15 & 15 & $30 \mathrm{~Gy}$ \\
20 & 20 & $40 \mathrm{~Gy}$ \\
25 & 25 & $50 \mathrm{~Gy}$ \\
30 & 30 & $60 \mathrm{~Gy}$ \\
\hline
\end{tabular}

As medidas de microdureza longitudinal, do esmalte e dentina, após a irradiação com Co-60 foram realizadas da mesma forma anteriormente descrita para a realização da microdureza pré-irradiação (Fluxograma 2). 


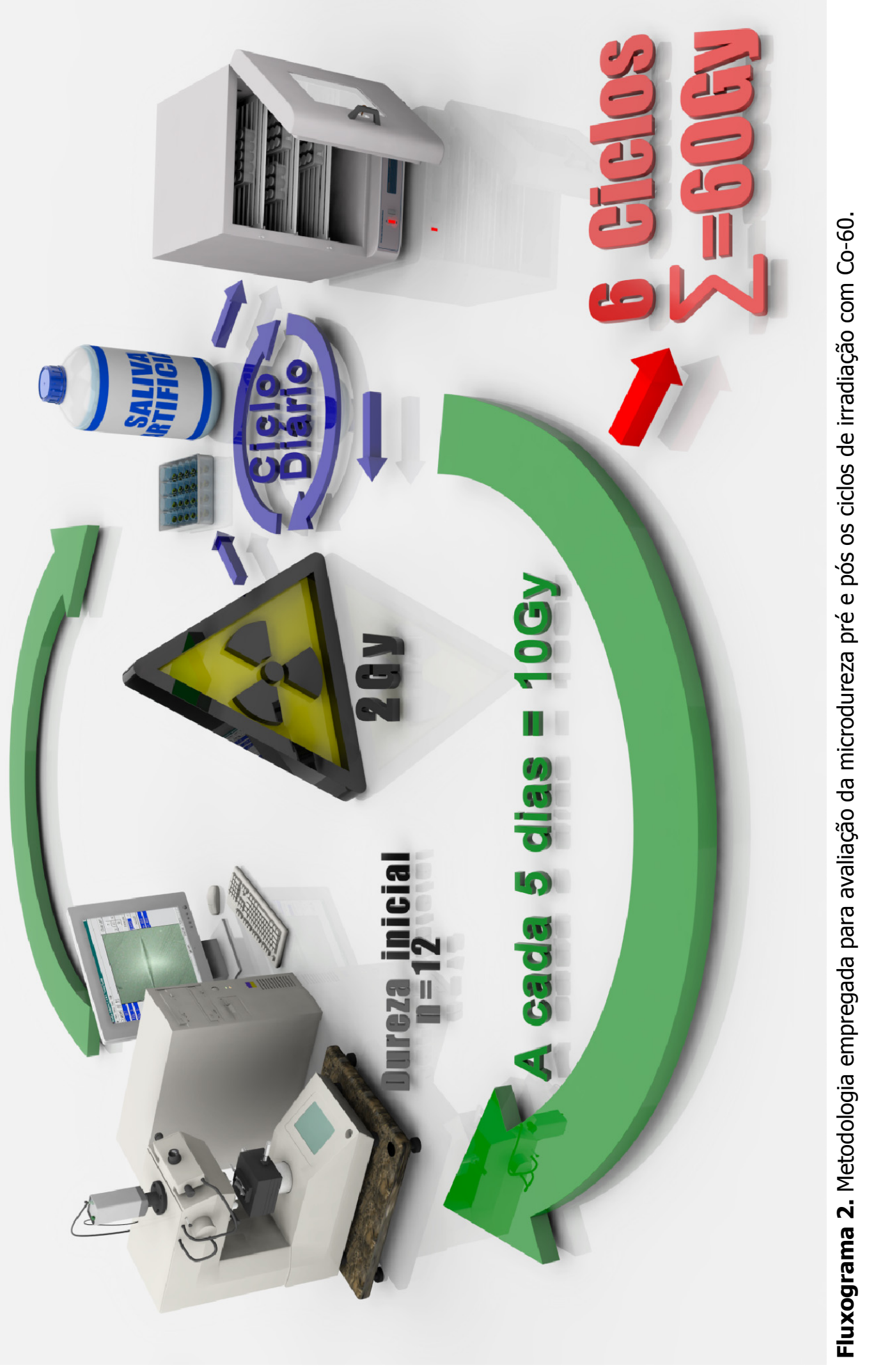




\subsection{AVALIAÇÃO EM MICROSCOPIA ELETRÔNICA DE VARREDURA (MEV)}

Para este experimento foram utilizadas 8 hemissecções dentais, que correspondiam a 2 hemissecções dentais irradiadas com uma dose cumulativa de 30 Gy, 2 hemissecções dentais irradiadas com uma dose cumulativa de 60 Gy e suas respectivas hemissecções não irradiadas.

Inicialmente, as hemissecções dentais foram submetidas ao seguinte protocolo: fixação (imersão em solução de glutaraldeído a 2,5 \% tamponado com solução de cacodilato de sódio a $0,1 \mathrm{M}$ com $\mathrm{Ph} 7,4$ ) em temperatura $4{ }^{\circ} \mathrm{C}$ por 12 horas; lavagem em água destilada por 3 minutos, limpeza em cuba ultrassônica (UltrasonicCleaner T-1449-D. Odontobrás Ind. E Com., Ribeirão Preto, Brasil) contendo água destilada e deionizada durante 10 minutos, aplicação de EDTA na dentina por 30 segundos, e aplicação de ácido fosfórico a 37 \% (Gel Etchant- Kerr Corporation, Orange, USA) no esmalte por 30 segundos, remoção e lavagem com água destilada, secagem, desidratação em graus crescentes de etanol (Labsynth Ltda., Diadema, Brasil): 25 \% (20 min), 50 \% (20 min), 75 \% (20 min), 95 \% (30 min) e $100 \%$ (60 min). Após a desidratação, as hemissecções foram imersas em solução de HMDS (Hexamethyldisiloxane-Merck KgaA, Darmstadt, D-64293, Alemanha) por 10 minutos para secagem química. Todos esses procedimentos foram realizados no interior de uma capela com o exaustor acionado.

Depois da secagem, as hemissecções dentais foram fixadas em stubs com fita adesiva de carbono, de dupla face (ElectronMicroscopySciences, Washigton, EUA) e a cobertura com ouro foi realizada em aparelho de metalização a vácuo (SDC 050, Bal-Tec AG, Foehrenwg 16, Balzers, Alemanha), com pressão de 0,01 mbar, corrente de 40 mA, distância de trabalho de $50 \mathrm{~mm}$, tempo de cobertura de 90 segundos e espessura média de deposição de 20 a $30 \mathrm{~nm}$. Em seguida, as secções dentais foram observadas em microscópio eletrônico de varredura (Philips XL30 FEG, Eindhoven, Holanda; disponibilizado pelo DEMa - Laboratório do Departamento de Engenharia de Materiais da Universidade Federal de São Carlos, São Paulo, Brasil) para verificação de possíveis alterações causadas nos substratos dentais (esmalte e dentina), obtendo-se eletromicrografias das áreas representativas. As áreas a serem analisadas corresponderam a toda espessura do esmalte e toda a espessura da dentina (comparação morfológica e qualitativa) (Fluxograma 3). 


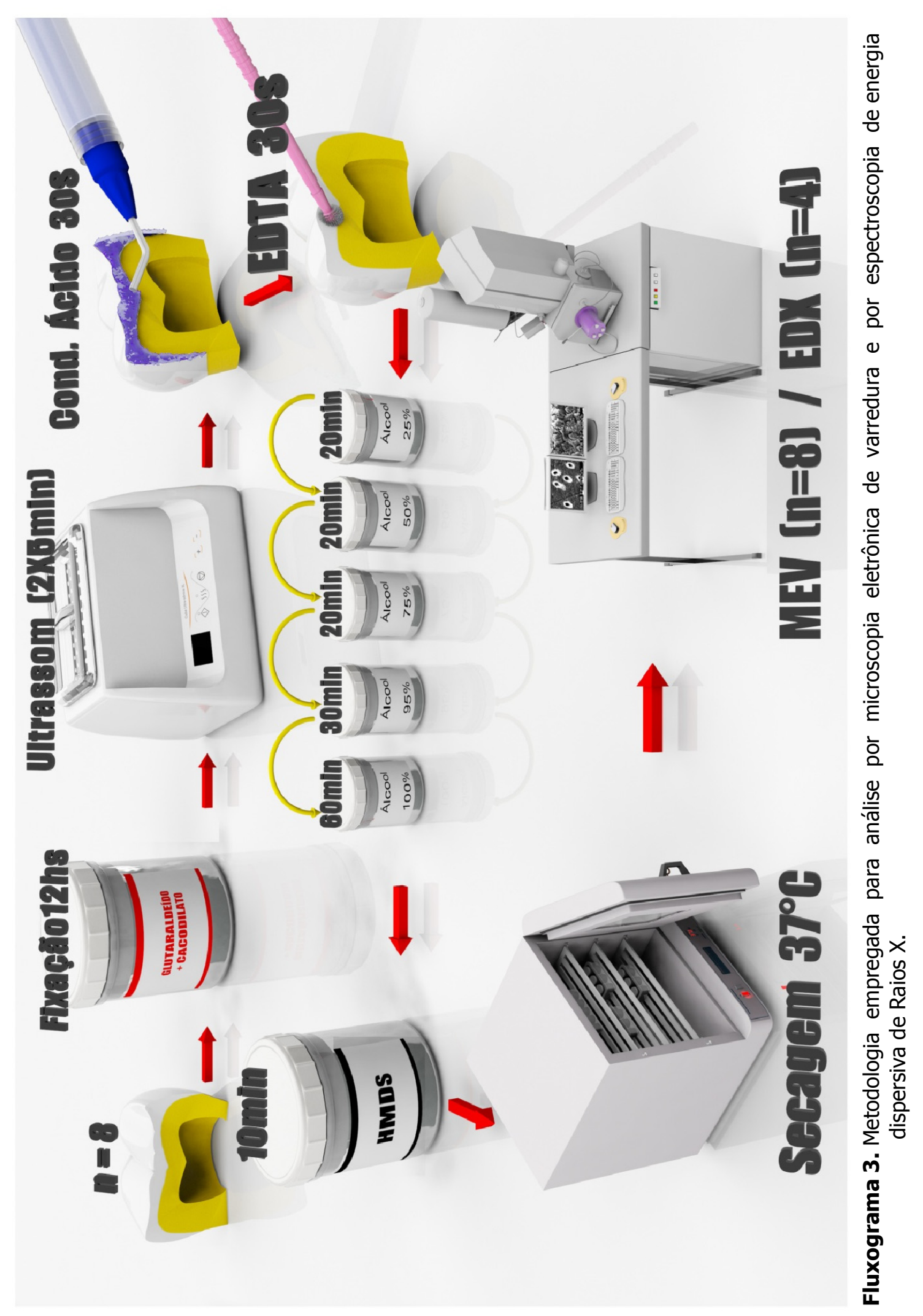




\subsection{AVALIAÇÃO POR ESPECTROSCOPIA DE ENERGIA DISPERSIVA DE RAIOS X (EDX)}

Quatro hemissecções dentais (2 hemissecções dentais irradiadas com dose cumulativa total de 60 Gy e suas respectivas hemissecções não irradiadas) foram submetidas à análise química por fluorescência de Raios X por energia dispersiva (Philips XL30 FEG, Eindhoven, Holanda, equipado com uma microsonda EDS de Raios $X$ para análise química, disponibilizado pelo DEMa - Laboratório do Departamento de Engenharia de Materiais da Universidade Federal de São Carlos, São Paulo, Brasil) (EDX). A superfície da amostra foi analisada longitudinalmente por dispersão de energia da radiação proveniente de um tubo de $\mathrm{Rh}$, posicionado a $90^{\circ}$ e acoplado a um sistema computadorizado. A amostra foi irradiada com feixe de raios $X$ de raio de $50 \mu \mathrm{m}$.

A voltagem do tubo foi de $50 \mathrm{kV}$, com um ajuste automático da corrente e um feixe de diâmetro de $50 \mu \mathrm{m}$. As medidas foram realizadas com um tempo de 100 segundos por ponto. Para cada amostra, o mapeamento dos componentes cálcio (Ca), oxigênio (O) e fósforo $(P)$ foi realizado em linha de $40 \times 1$ pontos, com passos de $10 \mu \mathrm{m}$, utilizando-se 50 $\mathrm{kV}$, em tempo real de aquisição (1 segundo por ponto), com um tempo final de escaneamento de 36 minutos por amostra.

Em todas as medidas, a contagem da radiação foi feita por um detector semicondutor de $\mathrm{Si}(\mathrm{Li})$ refrigerado por nitrogênio líquido. O reagente de hidroxiapatita estequiométrica sintética (Sigma-Aldrich; Sintra, Portugal), grau de pureza 99.99\% $\left[\mathrm{Ca}_{5} \mathrm{HO}_{13} \mathrm{P}_{3}\right]$, foi utilizado como referência de calibração. As condições analíticas foram baseadas no método dos parâmetros fundamentais. As variáveis para o cálculo da fórmula química foram estabelecidas para os pesos relativos de $\mathrm{Ca}, \mathrm{P}$ e $\mathrm{O}$, foi utilizado como balanço químico. O hidrogênio $(H)$ não foi considerado no balanço total de massa, uma vez que a sua massa é equivalente a apenas $0,1 \%$ do peso total da hidroxiapatita.

Após a realização do mapeamento, os espectros correspondentes a cada amostra foram tratados, utilizando o software do sistema do EDX (PCMEDX V. 1.04, Shimadzu Cor., Kyoto, Japan). Para análise descritiva dos dados, utilizou-se a concentração em peso dos elementos Ca, $\mathrm{P}$ e O (Fluxograma 3).

\subsection{ANÁLISE DOS DADOS}

Para a microdureza os dados foram analisados quanto à sua distribuição, a qual apresentou uma distribuição normal e homogênea, sendo a seguir submetidos à Análise de 
Variância a dois critérios. Para a diferenciação das médias, empregou-se o teste de Fisher. Com nível de significância de 5 \%.

Os dados obtidos em MEV e EDX não foram analisados estatisticamente uma vez que o objetivo da análise foi de uma comparação qualitativa das diferentes condições experimentais propostas no estudo. 


\section{RESULTADOS}

\subsection{AVALIAÇÃO DA MICRODUREZA LONGITUDINAL}

\subsubsection{ESMALTE DE DENTES DECÍDUOS}

Quando considerado o esmalte como um todo, isto é, não se fazendo distinções com relação à microdureza nas diferentes profundidades avaliadas, verificou-se que os valores médios de microdureza do esmalte variaram após as diferentes doses de irradiação. A irradiação influenciou na microdureza do esmalte, aumentando a significantemente após a dose de 60 Gy $(p<0,05)$. A dureza inicial (controle - não irradiado) apresentou menores valores que a final (após $60 \mathrm{~Gy})(p<0,05)$. De maneira geral, observou-se que conforme a dose de irradiação foi aumentada os valores de microdureza também sofreram ligeira elevação. Na dose cumulativa de 50 Gy os valores de microdureza foram diferentes dos valores de microdureza das doses de 10 Gy e 20 Gy. Após 60 Gy observou-se os maiores valores de microdureza (média de 211,4 KH), os quais apresentaram diferença estatisticamente significante $(p<0,05)$ dos valores de microdureza observados nas doses de 10 Gy, 20 Gy e 30 Gy e também do controle (Figura 1 e Tabela 2).

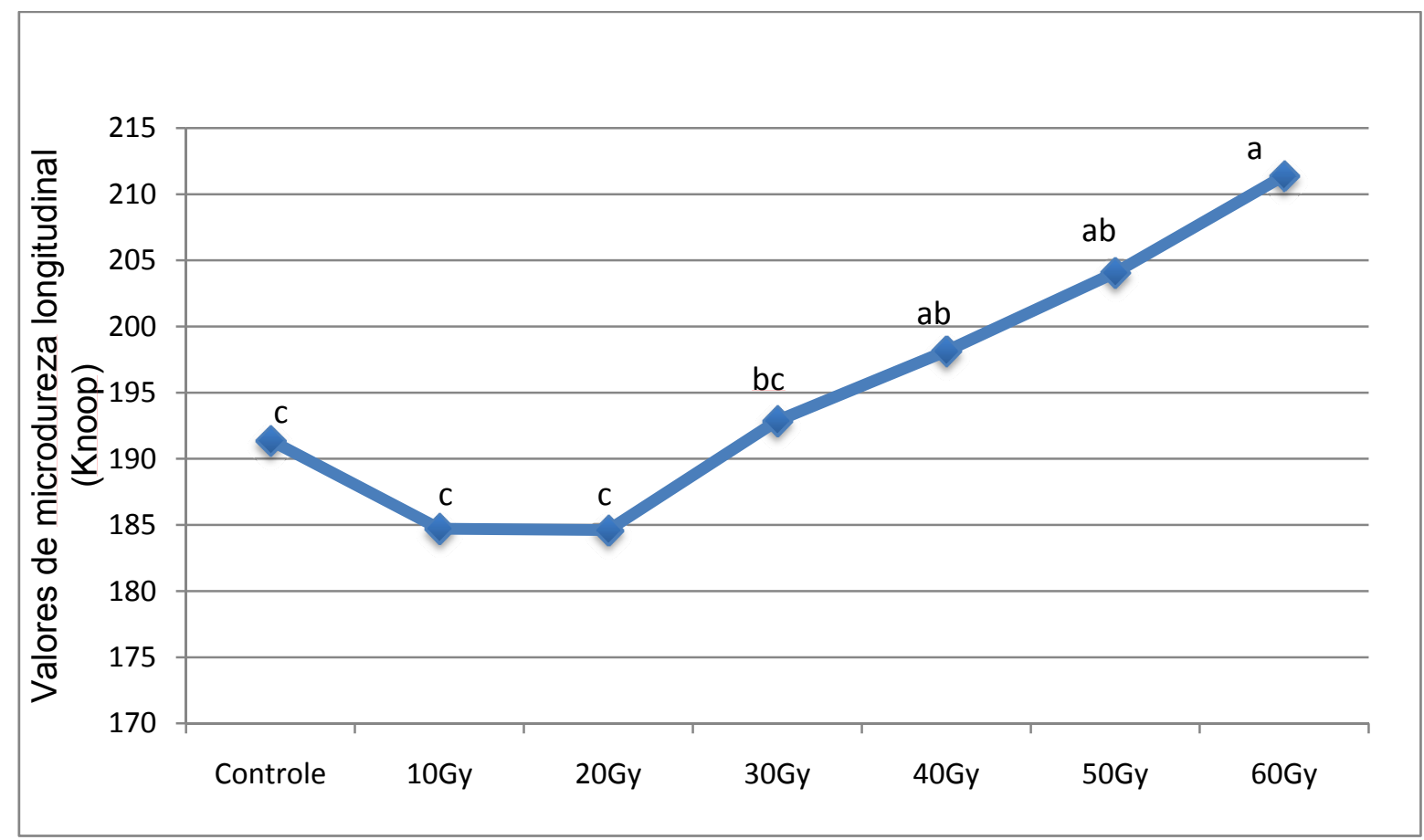

Figura 1 - Valores médios da microdureza longitudinal (Knoop) nas diferentes doses de irradiação. 
Tabela 2 - Valores médios da microdureza longitudinal (Knoop) nas diferentes doses de irradiação

\begin{tabular}{cc}
\hline GRUPO & MÉDIA \\
\hline Controle & $191,4^{\mathrm{c}}$ \\
$\mathbf{1 0}$ Gy & $184,7^{\mathrm{c}}$ \\
$\mathbf{2 0}$ Gy & $184,6^{\mathrm{c}}$ \\
$\mathbf{3 0}$ Gy & $192,9^{\mathrm{bc}}$ \\
$\mathbf{4 0}$ Gy & $198,2^{\mathrm{ab}}$ \\
$\mathbf{5 0}$ Gy & $204,1^{\mathrm{ab}}$ \\
$\mathbf{6 0}$ Gy & $211,4^{\mathrm{a}}$ \\
\hline
\end{tabular}

"comparação na coluna - mesmo símbolo similaridade estatistica

Quando consideradas as diferentes profundidades do esmalte, nas diferentes doses de irradiação, observou-se que no esmalte profundo foi encontrado o maior valor médio de microdureza $(206,7 \mathrm{KH})$, o qual foi estatisticamente diferente ( $p<$ $0,05)$ do valor médio das duas outras regiões avaliadas. No esmalte superficial foi observado o menor valor médio de microdureza $(184,8 \mathrm{KH})$, o qual também foi estatisticamente diferente do valor médio observado no esmalte médio (194,5 KH) ( $p<$ 0,05) (Figura 2 e Tabela 3).

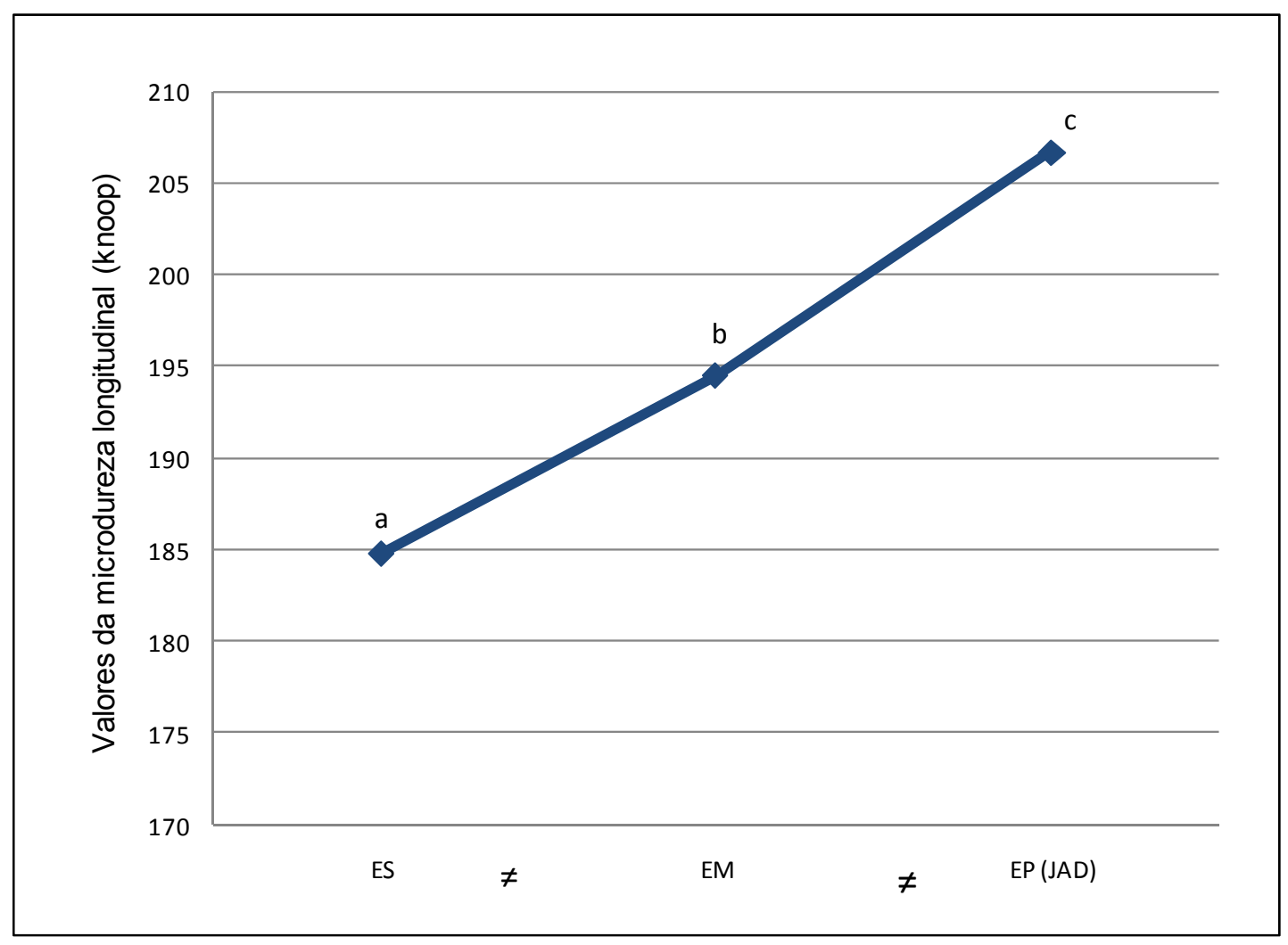

Figura 2 - Valores médios da microdureza longitudinal (Knoop), nas diferentes regiões do esmalte de dentes decíduos. 
Tabela 3 - Valores médios da microdureza longitudinal (Knoop), nas diferentes regiões do esmalte de dentes decíduos

\begin{tabular}{cc}
\hline GRUPO & MÉDIA \\
\hline Esmalte superficial & $184,8^{\mathrm{c}}$ \\
Esmalte médio & $194,5^{\mathrm{b}}$ \\
Esmalte profundo & $206,7^{\mathrm{a}}$ \\
\hline *comparação na coluna - mesmo sinal similaridade estatistica &
\end{tabular}

Analisando-se os valores de microdureza no esmalte não irradiado e irradiado, após diferentes doses de irradiação, nas diferentes profundidades, pode-se observar que no esmalte superficial, após a dose de $60 \mathrm{~Gy}$ os valores de microdureza foram diferentes dos valores de microdureza na dose de 10 Gy e $20 \mathrm{~Gy}(\mathrm{p}<0,05)$. Os valores de microdureza após a dose de 50 Gy foram diferentes estatisticamente apenas dos valores de microdureza após a dose de 10 Gy de irradiação (Tabela 4).

Na região correspondente ao esmalte médio verificou-se que os valores de microdureza após a dose 60 Gy foram diferentes dos valores de microdureza nas doses de 10 Gy, 20 Gy e 30 Gy e também do esmalte não irradiado (controle) ( $p<0,05$ ). Os valores de microdureza após a dose de $50 \mathrm{~Gy}$ foram diferentes estatisticamente dos valores de microdureza após a dose de 10 Gy e 20 Gy de irradiação (Tabela 4).

Finalmente, na região correspondente ao esmalte profundo não houve diferença estatisticamente significante $(p>0,05)$ entre os valores de microdureza, quando comparou-se as diferentes doses de irradiação e nem quando comparou-se com o controle (esmalte não irradiado) (Tabela 4).

Independentemente da profundidade do esmalte avaliada (esmalte superficial, esmalte médio e esmalte profundo) observou-se que após a primeira dose de irradiação (10 Gy) houve uma ligeira diminuição dos valores médios de microdureza, em comparação ao esmalte não irradiado. Entretanto nas doses subsequentes de irradiação (de 20 Gy a 60 Gy), observou-se um aumento gradativo nos valores médios da microdureza longitudinal do esmalte, dependendo da região do esmalte foi significante ou não (Tabela 4). 
Tabela 4 - Médias e desvios-padrões da microdureza longitudinal (Knoop) do esmalte de dentes decíduos, não irradiados e irradiados, após serem submetidos às diferentes doses de irradiação, nas diferentes profundidades

\begin{tabular}{|c|c|c|c|}
\hline & Esmalte superficial & Esmalte médio & Esmalte profundo \\
\hline $\begin{array}{l}\text { Controle (não } \\
\text { irradiado) }\end{array}$ & $180,13 \pm 36,85^{\mathrm{bc}}$ & $187,82 \pm 32,63^{B}$ & $206,22 \pm 51,41^{\boldsymbol{\Lambda}}$ \\
\hline Irradiado 10 Gy & $166,23 \pm 27,92^{c}$ & $182,89 \pm 24,22^{C}$ & $205,03 \pm 28,39^{\mathbf{4}}$ \\
\hline Irradiado 20 Gy & $173,00 \pm 42,78^{c}$ & $184,09 \pm 33,43^{C}$ & $196,78 \pm 28,70^{\mathbf{4}}$ \\
\hline Irradiado 30 Gy & $185,73 \pm 25,17^{b}$ & $187,11 \pm 20,63^{B}$ & $205,81 \pm 20,95^{\mathbf{\Lambda}}$ \\
\hline Irradiado 40 Gy & $188,03 \pm 43,49^{a}$ & $196,70 \pm 27,18^{\mathrm{AB}}$ & $209,72 \pm 23,97^{\mathbf{4}}$ \\
\hline Irradiado 50 Gy & $197,91 \pm 44,04^{\mathrm{ab}}$ & $205,64 \pm 17,65^{\mathrm{AB}}$ & $208,67 \pm 25,62^{\mathbf{4}}$ \\
\hline Irradiado 60 Gy & $202,30 \pm 17,71^{\mathrm{a}}$ & $217,42 \pm 25,33^{A}$ & $214,47 \pm 25,99^{\mathbf{4}}$ \\
\hline
\end{tabular}

\subsubsection{DENTINA DE DENTES DECÍDUOS}

Quando considerada a dentina como um todo, isto é, não se fazendo distinção com relação à microdureza nas diferentes profundidades avaliadas, verificou-se que, de maneira geral, os valores médios de microdureza da dentina variaram após as diferentes doses de irradiação. Observou-se diferença estatisticamente significante entre os valores de microdureza da dentina não irradiada (controle) com relação à dentina irradiada com doses de $10 \mathrm{~Gy}, 20 \mathrm{~Gy}, 30 \mathrm{~Gy}$ e $40 \mathrm{~Gy}(\mathrm{p}<0,05)$. As doses $50 \mathrm{~Gy}$ e $60 \mathrm{~Gy}$ apresentaram o mesmo valor médio de microdureza $(26,7 \mathrm{KH})$ e diferente da dose de 10 Gy de irradiação $(p<0,05)$. Com 60 Gy de irradiação observou-se que o valor médio de microdureza não apresentou diferença estatisticamente significante quando comparado ao valor médio de microdureza da dentina não irradiada (controle) $(p>0,05)$ (Figura 3 e Tabela 5). 


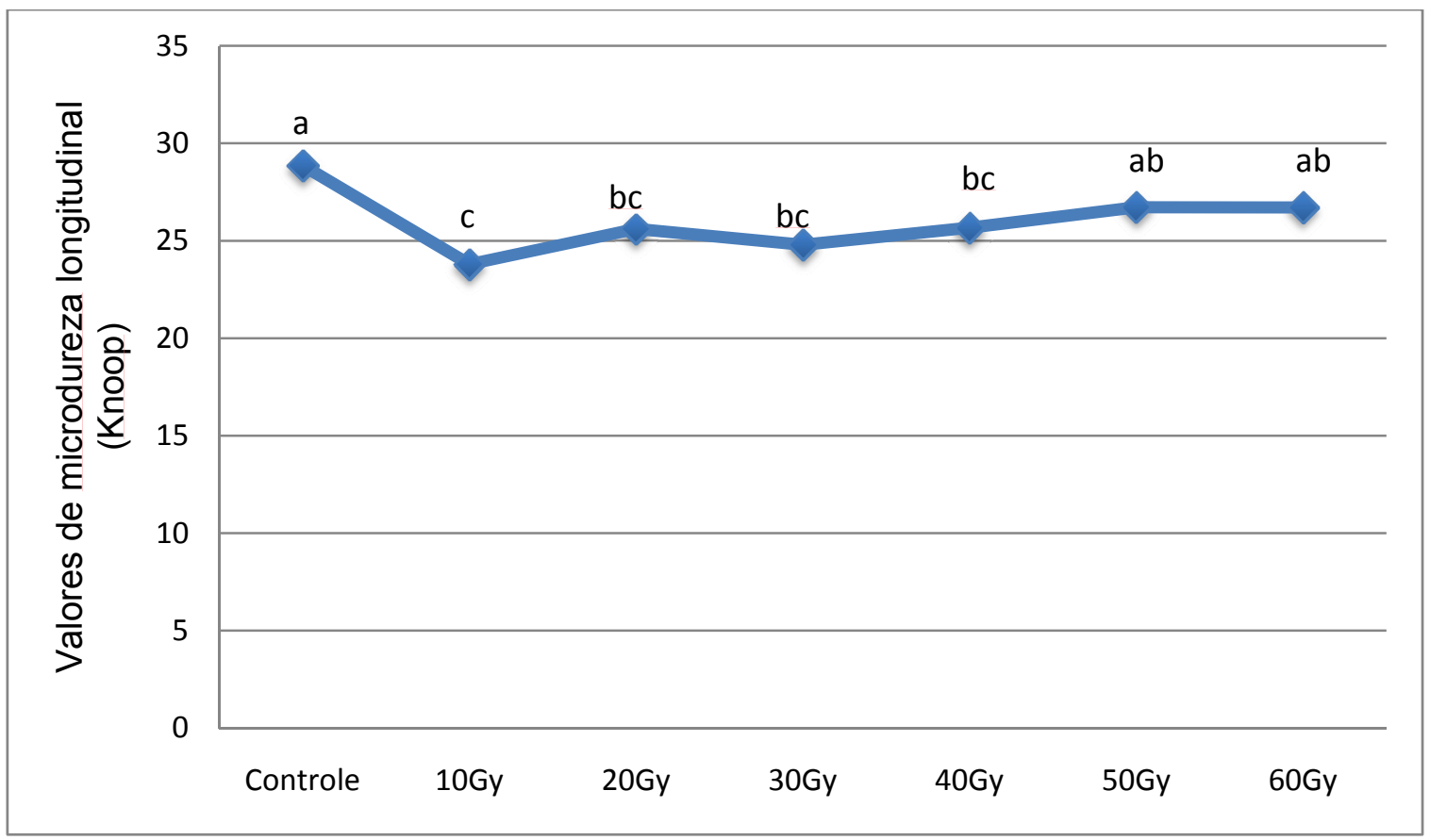

Figura 3 - Valores médios da microdureza longitudinal (Knoop) nas diferentes doses de irradiação.

Tabela 5 - Valores médios da microdureza longitudinal (Knoop) nas diferentes doses de irradiação

\section{GRUPO}

Controle

$10 \mathrm{~Gy}$

$20 \mathrm{~Gy}$

30 Gy

40 Gy

50 Gy

$60 \mathrm{~Gy}$

\section{MÉDIA}

$28,9^{\mathrm{a}}$

$23,8^{\mathrm{C}}$

$25,6^{\text {bc }}$

$24,8^{\text {bc }}$

$25,7^{\mathrm{bc}}$

$26,7^{\mathrm{ab}}$

$26,7^{\mathrm{ab}}$

Quando consideradas as diferentes profundidades da dentina, nas diferentes doses de irradiação, observou-se que na dentina média foi encontrado o maior valor médio de microdureza $(29,9 \mathrm{KH})$, o qual foi estatisticamente diferente $(p<0,05)$ das outras regiões avaliadas. Na dentina profunda foi observado o menor valor médio de microdureza $(20,8 \mathrm{KH})$, o qual também foi estatisticamente diferente do valor médio observado na dentina superficial $(23,4 \mathrm{KH})(\mathrm{p}<0,05)$ (Figura 4 e Tabela 6$)$. 


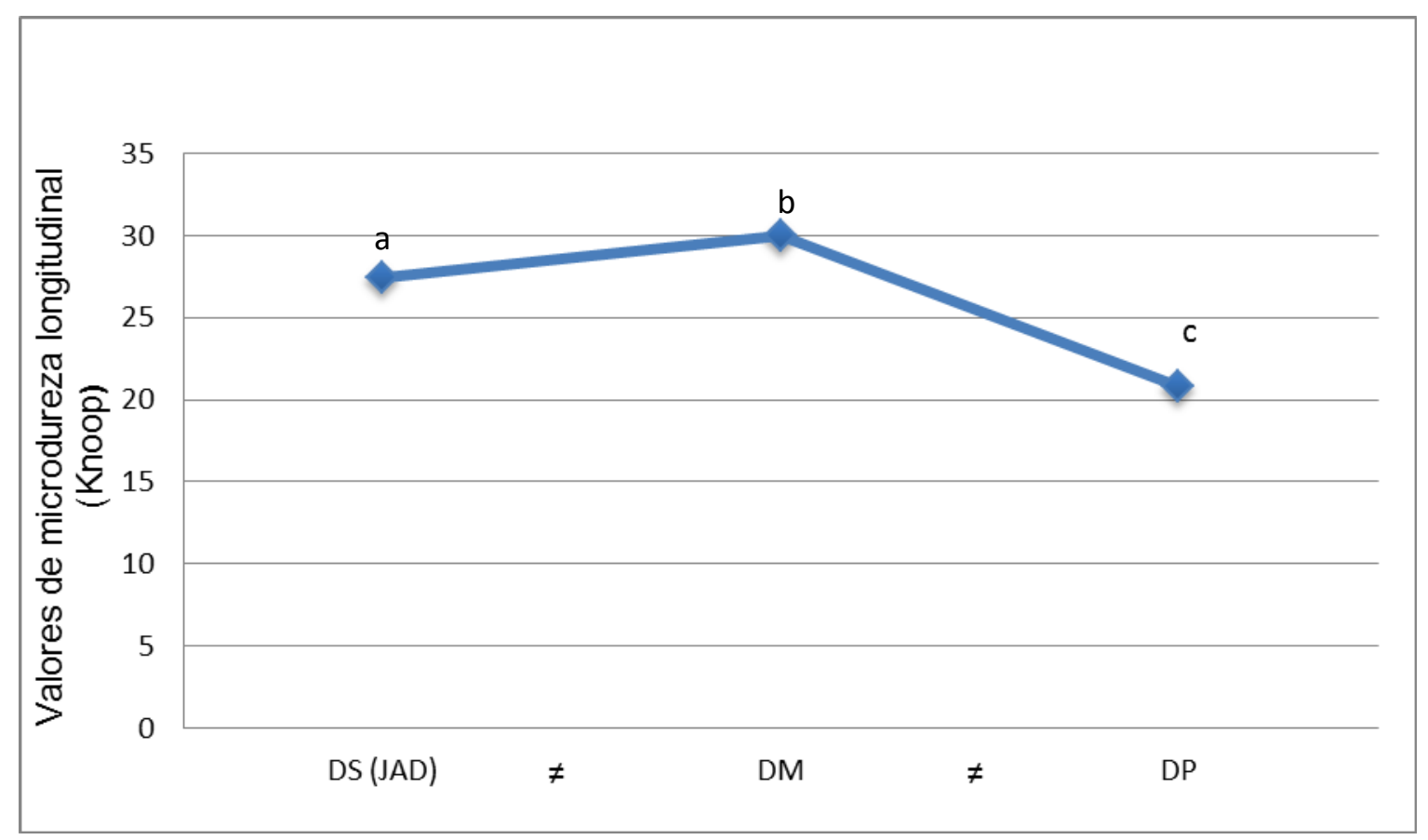

Figura 4 - Valores médios da microdureza longitudinal (Knoop) nas diferentes regiões da dentina após irradiação.

Tabela 6 - Valores médios da microdureza longitudinal (Knoop) nas diferentes regiões da dentina após irradiação

GRUPO MÉDIA

\begin{tabular}{cc}
\hline Dentina superficial & $23,4^{\mathrm{b}}$ \\
Dentina média & $29,9^{\mathrm{a}}$ \\
Dentina profunda & $20,8^{\mathrm{c}}$ \\
\hline *comparação na coluna - mesmo sinal similaridade estatistica $^{2}$
\end{tabular}

Analisando-se os valores de microdureza na dentina não irradiada e irradiada, após diferentes doses de irradiação, nas diferentes profundidades, pode-se observar que na dentina superficial o valor médio de microdureza no controle (dentina não irradiada), foi de $30,8 \mathrm{KH}$, o qual foi diferente dos valores médios de microdureza nas doses de 10 Gy, 20 Gy, 30 Gy e 40 Gy (p < 0,05). Nesta região, com 60 Gy de irradiação observou-se que os valores médios de microdureza não apresentaram diferença estatisticamente significante, em comparação à dentina não irradiada (controle) ( $p$ > 0,05) (Tabela 7).

$\mathrm{Na}$ região correspondente à dentina média não houve diferença estatisticamente significante entre os valores médios de microdureza nas diferentes doses de irradiação e nem com relação à dentina não irradiada $(p>0,05)$ (Tabela 7).

Finalmente, na região correspondente à dentina profunda, verificou-se que houve diferença estatisticamente significante $(p<0,05)$ apenas entre o valor médio de 
microdureza da dentina não irradiada (controle) com a dentina irradiada após dose de 10 Gy $(p<0,05)$. Os valores de microdureza após a dose de $60 \mathrm{~Gy}$ não foram diferentes dos valores de microdureza após as diferentes doses de irradiação e nem com relação à dentina não irradiada ( $p>0,05)$ (Tabela7).

Independentemente das profundidades da dentina avaliadas (dentina superficial; dentina média e dentina profunda), observou-se que os valores médios de microdureza após a dose de 60 Gy não foram diferentes estatisticamente dos valores médios de microdureza após as diferentes doses de irradiação e nem com relação à dentina não irradiada ( $p>0,05$ ) (Tabela 7).

Tabela 7 - Médias e desvios-padrões da microdureza longitudinal (Knoop) da dentina de dentes decíduos, não irradiadas e irradiadas, após diferentes doses de irradiação, nas diferentes profundidades

\begin{tabular}{|c|c|c|c|}
\hline & $\begin{array}{c}\text { Dentina } \\
\text { superficial }\end{array}$ & Dentina média & $\begin{array}{l}\text { Dentina } \\
\text { profunda }\end{array}$ \\
\hline $\begin{array}{l}\text { Controle (não } \\
\text { irradiado) }\end{array}$ & $30,81 \pm 5,06^{a}$ & $31,53 \pm 7,94^{\boldsymbol{\Lambda}}$ & $24,24 \pm 8,47^{A}$ \\
\hline Irradiado 10 Gy & $25,22 \pm 4,66^{b}$ & $27,41 \pm 7,52^{\wedge}$ & $18,79 \pm 6,18^{\mathrm{B}}$ \\
\hline Irradiado 20 Gy & $26,07 \pm 3,32^{b}$ & $31,51 \pm 5,59^{\Delta}$ & $19,26 \pm 3,33^{A B}$ \\
\hline Irradiado 30 Gy & $26,50 \pm 5,31^{b}$ & $28,86 \pm 6,78^{\wedge}$ & $19,03 \pm 5,20^{A B}$ \\
\hline Irradiado 40 Gy & $26,54 \pm 3,53^{b}$ & $28,98 \pm 5,07^{\Delta}$ & $21,50 \pm 8,08^{A B}$ \\
\hline Irradiado 50 Gy & $28,48 \pm 2,98^{\mathrm{ab}}$ & $30,82 \pm 5,49^{\wedge}$ & $20,86 \pm 7,08^{A B}$ \\
\hline Irradiado 60 Gy & $27,84 \pm 3,13^{\mathrm{ab}}$ & $30,37 \pm 6,76^{\wedge}$ & $21,92 \pm 5,78^{\mathrm{AB}}$ \\
\hline
\end{tabular}

\subsection{AVALIAÇÃo EM MICROSCOPIA ELETRÔNICA DE VARREDURA (MEV)}

\subsubsection{ESMALTE DE DENTES DECÍDUOS}

$\mathrm{Na}$ análise morfológica do esmalte, por meio da MEV, pode-se observar que o esmalte dos dentes não irradiados (controle) apresentava-se com prismas bem organizados, circundados pelas regiões interprismáticas, observados em secções transversas e oblíquas.

As figuras 5, 6 e 7 correspondem a eletromicrografias de espécimes representativos do padrão morfológico observado nas regiões do esmalte. 
As eletromicrografias dos grupos irradiados com dose de 30 Gy e 60 Gy mostraram alteração crescente da superfície do esmalte, em comparação ao esmalte não irradiado para todas as regiões analisadas. Com o aumento progressivo das doses de irradiação pode-se observar alteração também progressiva da estrutura prismática do esmalte, dificultando a identificação dos prismas. Após a exposição de $60 \mathrm{~Gy}$, a superfície apresentou-se amorfa, não sendo possível a visualização dos prismas e dos cristais de hidroxiapatita, inclusive ocorrendo a perda de definição do espaço interprismático (Figuras 5, 6 e 7). 

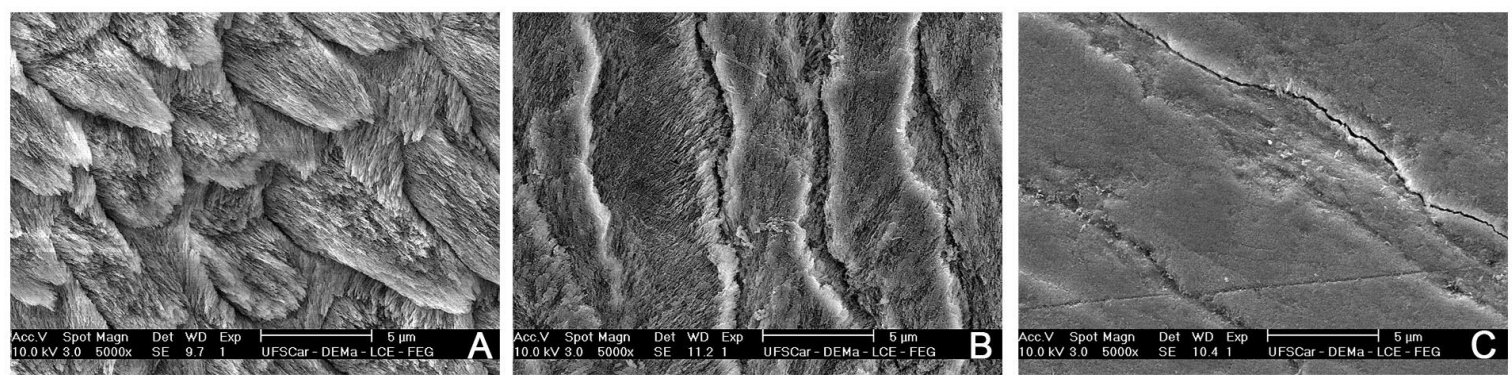

Figura 5 - Eletromicrografias do esmalte de dentes decíduos, obtidas por meio de microscopia eletrônica de varredura, com aumento de 5000x. A- esmalte não irradiado (Controle) ; Besmalte irradiado (30 Gy); C- esmalte irradiado (60 Gy).
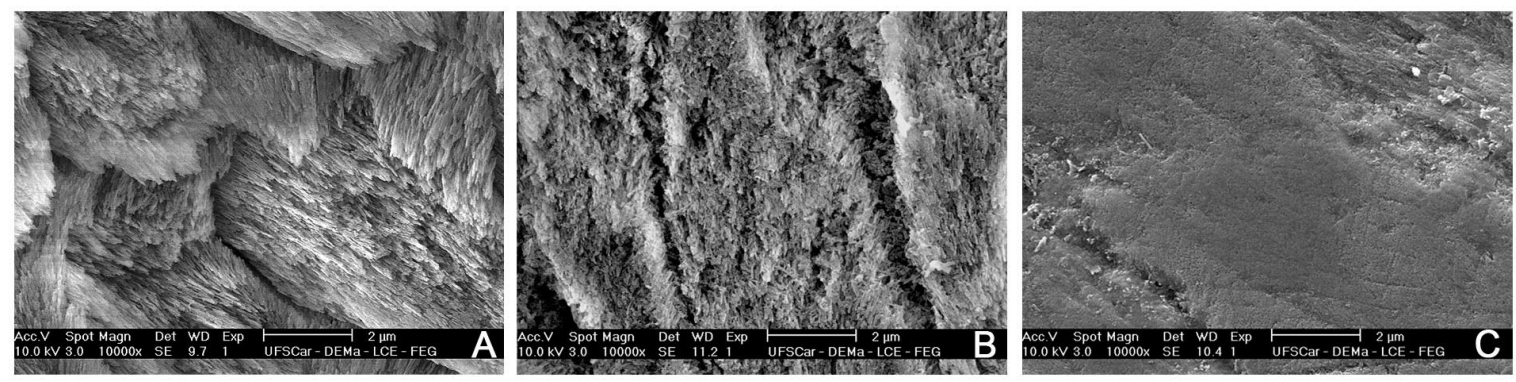

Figura 6 - Eletromicrografias do esmalte de dentes decíduos, obtidas por meio de microscopia eletrônica de varredura, com aumento de $10000 x$. A- esmalte não irradiado; B- esmalte irradiado (30 Gy); C- esmalte irradiado (60 Gy).
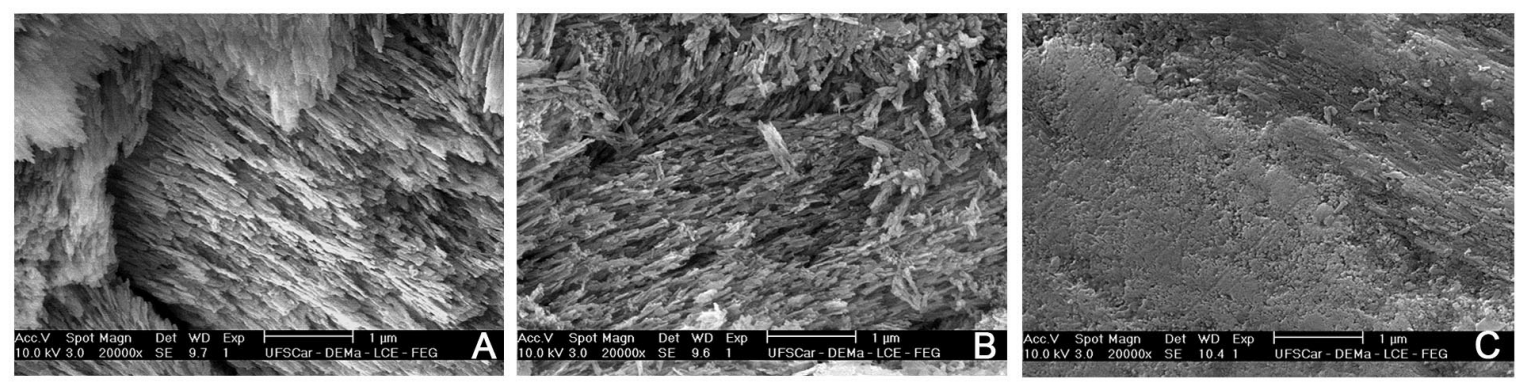

Figura 7 - Eletromicrografias do esmalte de dentes decíduos, obtidas por meio de microscopia eletrônica de varredura, com aumento de 20000x. A- esmalte não irradiado; B- esmalte irradiado (30 Gy); C- esmalte irradiado (60 Gy). 


\subsubsection{DENTINA DE DENTES DECÍDUOS}

$\mathrm{Na}$ análise morfológica da dentina, por meio da microscopia eletrônica de varredura pode-se observar que a dentina dos dentes não irradiados (controle) apresentava-se com túbulos dentinários bem definidos, com a rede de colágeno bem organizada.

As figuras 8, 9 e 10 correspondem a eletromicrografias de espécimes representativos do padrão morfológico observado nas regiões da dentina.

As eletromicrografias dos grupos irradiados com dose de 30 Gy e 60 Gy mostraram alteração crescente da superfície, em comparação à dentina não irradiada em todas as regiões avaliadas. Com o aumento progressivo das doses de irradiação pode-se observar alteração da dentina intertubular e peritubular, sendo que nos aumentos de 10000 e 20000 vezes (Figuras 9 e 10), respectivamente, pode-se observar a degradação da rede de colágeno. Após a exposição de 60 Gy, a superfície apresentou-se amorfa, com dificuldade de identificação dos túbulos dentinários, da rede de fibras colágenas e dos cristais de hidroxiapatita. 

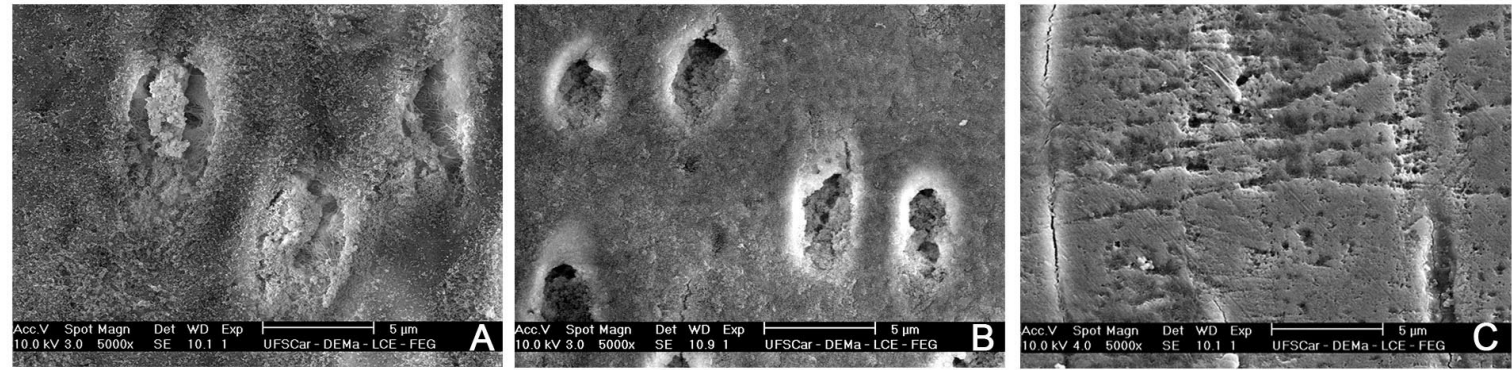

Figura 8 - Eletromicrografias da dentina de dentes decíduos, obtidas por meio de microscopia eletrônica de varredura, com aumento de 5000x. A- dentina não irradiada; B- dentina irradiada (30 Gy); C- dentina irradiada (60 Gy).
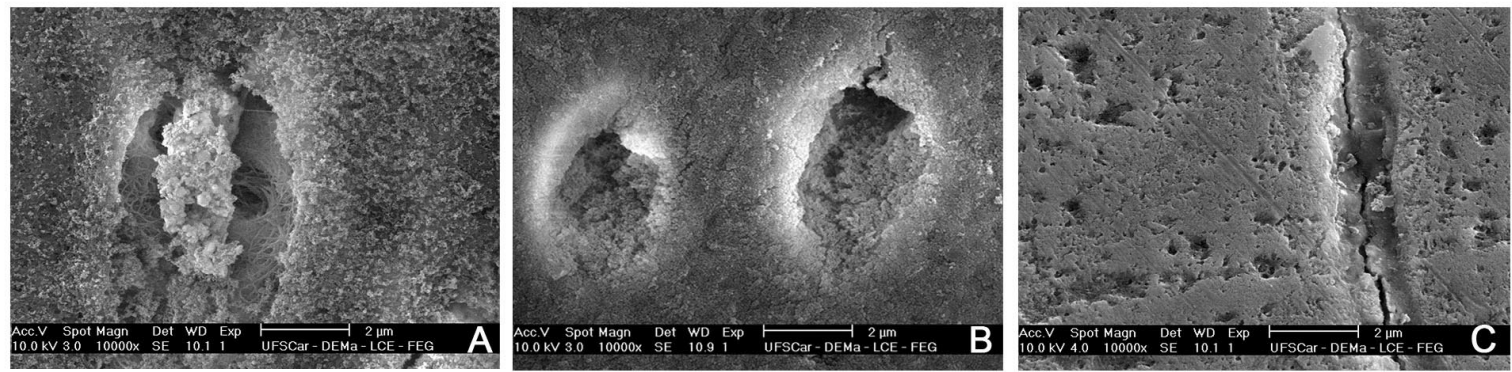

Figura 9 - Eletromicrografias da dentina de dentes decíduos, obtidas por meio de microscopia eletrônica de varredura, com aumento de 10000x. A- dentina não irradiada; B- dentina irradiada (30 Gy); C- dentina irradiada (60 Gy).
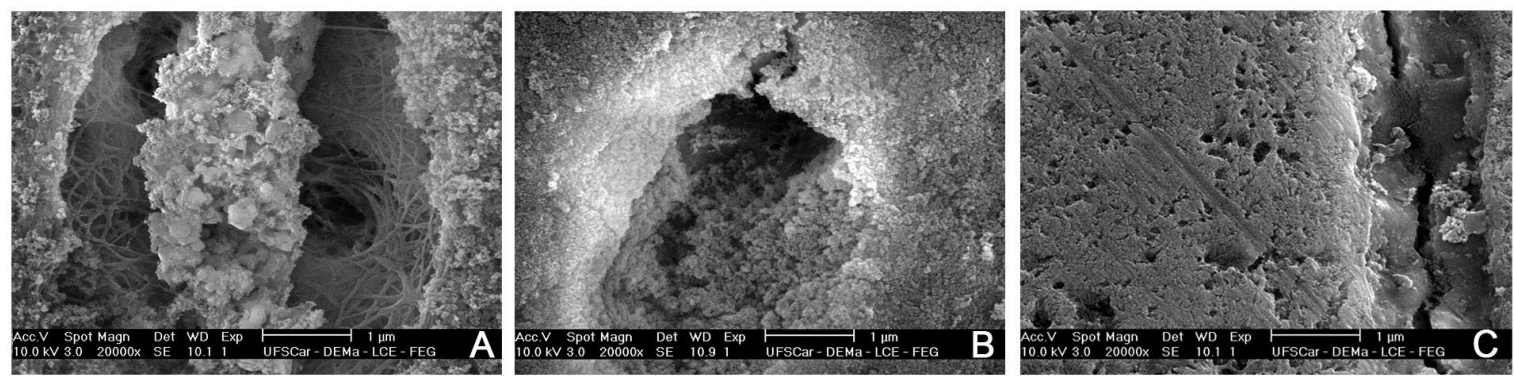

Figura 10 - Eletromicrografias da dentina de dentes decíduos, obtidas por meio de microscopia eletrônica de varredura, com aumento de 20000x. A- dentina não irradiada; B- dentina irradiada (30 Gy); C- dentina irradiada (60 Gy). 


\subsection{AVALIAÇÃO POR ESPECTROSCOPIA DE ENERGIA DISPERSIVA DE RAIOS X (EDX)}

Na análise da composição e quantificação dos íons por meio da Espectroscopia de Energia Dispersiva de Raios X (EDX) foram analisadas as porcentagens dos elementos químicos: cálcio $(\mathrm{Ca})$, oxigênio $(\mathrm{O})$ e fósforo $(\mathrm{P})$, no esmalte e dentina de dentes decíduos irradiados e seus respectivos controles não irradiados.

Tabela 8 - Percentual médio de elementos químicos presentes no esmalte de dentes decíduos não irradiados e irradiados (60 Gy)

\section{ELEMENTOS QUÍMICOS ESMALTE NÃO- IRRADIADO ESMALTE IRRADIADO} (CONTROLE)

\begin{tabular}{ccc}
\hline Oxigênio (O) & 35,56 & 30,33 \\
Fósforo (P) & 19,93 & 19,21 \\
Cálcio (Ca) & 45,54 & 50,46 \\
\hline
\end{tabular}

Tabela 9 - Percentual médio de elementos químicos presentes na dentina de dentes decíduos não irradiados e irradiados (60 Gy)

ELEMENTOS QUÍMICOS

\section{DENTINA NÃO- IRRADIADA DENTINA IRRADIADA (CONTROLE)}

\begin{tabular}{ccc}
\hline Oxigênio (O) & 38,19 & 32,24 \\
Fósforo (P) & 17,55 & 18,91 \\
Cálcio (Ca) & 44,27 & 48,86 \\
\hline
\end{tabular}

De acordo com os dados obtidos pode-se inferir que houve uma redução na porcentagem de oxigênio no esmalte e na dentina irradiados com dose total de $60 \mathrm{~Gy}$, quando comparada com os respectivos grupos controles não irradiados. Por outro lado, a porcentagem de cálcio foi maior no esmalte e na dentina irradiado, quando comparada com os respectivos grupos controles não irradiados. O fósforo apresentou pouca alteração entre os espécimes. 


\section{DISCUSSÃo}

\subsection{METODOLOGIA}

A radioterapia é um tratamento comumente utilizado em indivíduos portadores de tumores, que pode levar a danos teciduais leves ou severos (Langland e Langlais, 2002; Jham et al., 2008; Lôbo e Martins, 2009). As complicações provenientes da radioterapia podem variar de acordo com o tipo histológico da neoplasia, com o local e o volume da área a ser irradiada, com a dose, o ritmo de aplicação, o tipo de radiação e as condições gerais do paciente (Cardoso et al., 2005).

As doses para tratamento de câncer variam de 50 a $70 \mathrm{~Gy}$, dependendo do tumor e da rotina hospitalar aplicada. A dose comum de irradiação para o tratamento de carcinomas espinocelulares de cabeça e pescoço costuma variar entre 60 e 70 Gy. A dose diária é normalmente $2 \mathrm{~Gy} /$ dia, 5 dias/semana - intercalada por 2 dias sem radiação, correspondente aos finais de semana, a fim de que os tecidos sadios adjacentes ao tumor possam se recuperar (Huber e Terezhalmy, 2003; Vissink et al., 2003; Kielbassa et al., 2006).

A natureza da irradiação também tem influência sobre a dose e, consequentemente, sobre as complicações (Engelmeier e King, 1983). No presente estudo o protocolo empregado para a terapia de radiação foi o mesmo rotineiramente utilizado para o tratamento de pacientes com câncer de cabeça e pescoço. A dose-fração incremental diária de $2 \mathrm{~Gy} /$ dia, conseguida por meio do aparelho de telecobalterapia, foi utilizada para simular a dose de radiação que os pacientes oncológicos recebem diariamente.

Este estudo foi realizado segundo protocolos de radiação previamente descritos e validados na literatura (Jansma et al., 1988; Jansma et al., 1990; Pioch et al., 1992; Kielbassa et al., 1997; Kielbassa et al., 1999; Al-Nawas et al., 2000; Kielbassa, 2000; Springer et al., 2005; Soares et al., 2010; Kielbassa et al., 2000; Soares et al., 2011). Como o objetivo deste trabalho foi simular as condições clínicas do tratamento radioterápico foi feita a opção pela dose de 60 Gy (Anneroth et al.,1985; Jansma et al., 1993; Jham e da Silva Freire, 2006; Otmani, 2007), e pela manutenção em saliva artificial durante a irradiação, com a finalidade de simular o mais precisamente possível as condições encontradas na cavidade bucal (Soares et al., 2011), Entretanto, diferentes estudos com dentes permanentes utilizaram outras substâncias tais como solução salina a 0,9 \% (Jansma et al., 1990; Kielbassa et al., 1997; Al-Nawas et al., 2000; Kielbassa et al., 2000), água destilada (Jansma et al., 1988; Soares et al., 2010) ou solução fosfatada tamponada (Pioch et al., 1992). Contudo, ainda não existem estudos que definam qual seria a melhor solução de 
armazenamento em dentes submetidos à radioterapia in vitro (Soares et al., 2011). Embora se saiba que a saliva artificial não reproduza exatamente as características da saliva natural, principalmente, no caso de pacientes submetidos à radioterapia de cabeça e pescoço onde o fluxo, a secreção e a composição da saliva sofrem alterações significativas (Vuolita et al., 2002; Hannig et al., 2006), no presente trabalho optou-se por usar a saliva artificial, que de acordo com Amaechi et al., (2001) corresponderia à saliva natural, em indivíduos não submetidos à irradiação de cabeça e pescoço em relação à composição e viscosidade.

Estudos (Jansma et al., 1993; Silverman, 1999; Andrews e Griffiths, 2001; Craddock, 2006; Jham e da Silva Freire, 2006) observaram que as causas das lesões de cárie de radiação, ocorrem principalmente em função da xerostomia ocasionada pelos danos da radiação às glândulas salivares. No entanto, o conhecimento acerca das alterações estruturais que ocorrem na dentina e no esmalte de dentes permanentes após a irradiação, ainda não é totalmente compreendido (Soares et al., 2011; Jansma et al., 1990; Kielbassa et al., 1997; Al-Nawas et al., 2000; Kielbassa et al., 2000; Jansma et al., 1988; Soares et al., 2010; Pioch et al., 1992; Fränzel e Gerlach, 2006). As diferenças nos resultados ocorrem, provavelmente, devido à falta de padronização da metodologia utilizada nos diferentes estudos que avaliam os danos radiogênicos diretos ao esmalte e dentina. Estes trabalhos empregam diferentes substratos dentais, bovinos (Jansma et al., 1988, 1990; Pioch et al., 1992; Kielbassa et al., 1997) ou humanos (Jansma et al., 1993; Kielbassa, 2000; Kielbassa et al., 1999, 2000; Al-Nawas et al., 2000; Fränzel e Gerlach, 2006; Soares et al., 2010; Soares et al., 2011) e diferentes doses de radiação (Grötz et al., 1997,1998 e 2001) para estudos in vitro, in situ e in vivo, com dentes permanentes.

$\mathrm{Na}$ presente pesquisa empregou-se dentes decíduos obtidos de humanos, com a finalidade de avaliar os efeitos da irradiação nessa dentição, considerando que existem diferenças morfológicas, estruturais e de composição entre dentes decíduos e permanentes (De Menezes Oliveira et al., 2010). Entretanto, até o presente momento, a ausência de estudos empregando dentes decíduos impossibilita uma comparação direta dos resultados obtidos no presente trabalho.

Considerando os efeitos deletérios da radiação ionizante sobre as estruturas dentais, possivelmente em função da alteração nas propriedades mecânicas dos dentes, este estudo avaliou a microdureza longitudinal de dentes decíduos submetidos à irradiação com Co-60, utilizando o ensaio de microdureza de Knoop, com carga 25 gf para esmalte e 10 gf para dentina. A microscopia eletrônica de varredura foi também realizada, por ser um método qualitativo e por possibilitar a observação do esmalte e da dentina de dentes decíduos após 
a irradiação dos espécimes. A avaliação com EDX foi empregado com o intuito de fornecer informações relativas às alterações na composição química dos espécimes após irradiação.

\subsection{ALTERAÇÕES NO ESMALTE DE DENTES DECÍDUOS}

O esmalte dentário é o tecido mineralizado mais duro do corpo humano, apresentando $96 \%$ em peso de conteúdo inorgânico, associado a $4 \%$ de água e material orgânico. A porção mineral é representada por fosfato de cálcio cristalino e apatita, nas formas de hidroxiapatita, apatita carbonatada ou apatita fluoretada (Meckel et al., 1965; Stack, 1954; Gwinnett, 1992; De Menezes Oliveira et al., 2010). Os elementos químicos que compõem a base desse tecido são o cálcio e o fosfato (Brudevold et al., 1963). Variações secundárias ocorrem na sua composição, em que os elementos químicos, como alumínio, bário, estrôncio e vanádio, também podem ser encontrados (Gwinnett, 1992; Saleh et al., 2004).

De modo complementar, o conteúdo mineral do esmalte de dentes decíduos foi quantificado no presente estudo com auxílio da microanálise, baseada na espectroscopia de energia dispersiva de raios $X$ (EDX). No esmalte irradiado foi observado o valor médio de $19,21 \%$ de fósforo (P), 50,46 \% de cálcio ( $\mathrm{Ca}$ ) e 30,33 \% de oxigênio (O), enquanto no esmalte não irradiado foi observado $19,93 \%$ de fósforo, 45,54 \% de cálcio e 35,56 \% de oxigênio, semelhante ao observado por De Menezes Oliveira et al. (2010) empregando substrato não irradiado, onde a variação percentual pode ser explicada pelo local onde foi realizado a quantificação de íons nos diferentes trabalhos.

A pequena variação no conteúdo do cálcio ( $\mathrm{Ca}$ ) pode ter ocorrido em virtude do fato de que a irradiação pode levar a alterações estruturais e morfológicas, que ocasionam um aumento de porosidade no substrato, como visto na MEV, quando imerso em saliva artificial pode sofrer uma deposição de minerais. Entretanto como método só permite a análise dos elementos químicos presentes no tecido não se sabe se os elementos apresentam um aumento da quantidade de fase química ou a formação de uma nova fase.

$\mathrm{Na}$ literatura, alguns autores relatam a existência de uma camada aprismática de 30 $\mu \mathrm{m}$ de espessura na superfície do esmalte dos dentes decíduos, mais espessa e uniforme, em comparação ao esmalte dos dentes permanentes (Fava et al., 1993;1997; De Menezes Oliveira et al., 2010). Neste estudo, a camada aprismática possivelmente não influenciou os resultados obtidos uma vez que os ensaios foram realizados a partir de $50 \mu \mathrm{m}$ da superfície do esmalte. 
Com relação à microdureza longitudinal, do esmalte os resultados do presente estudo mostraram que a irradiação levou ao aumento da microdureza de maneira dose-dependente, com a dose cumulativa de 60 Gy apresentando os maiores valores. Estes resultados são divergentes de estudos prévios em dentes permanentes que demonstraram que a microdureza do esmalte irradiado foi menor que do esmalte não irradiado (Poyton, 1968) ou que não havia alteração da microdureza em função da irradiação (Shannon et al., 1978; Markitziu et al., 1986; Jansma et al., 1988; Kielbassa et al., 1999; Shaw et al., 2000).

Ainda que tenha sido sugerido que alterações provenientes da irradiação promovam alterações químicas na microestrutura do esmalte e não alterações físicas (Kielbassa et al., 1999), a re-estruturação da estrutura cristalina dos tecidos mineralizados (Fisher et al., 1971; Markitziu et al., 1986; Knychalska-Karwan et al., 1988) pode exercer um efeito sobre a resistência mecânica (Jervoe, 1970), sendo que a resistência à tração foi reduzida em dentes irradiados, em comparação aos dentes não irradiados, indicando que existam alterações mecânicas na estrutura dental em função da irradiação (Soares et al., 2011).

A microdureza do esmalte foi influenciada pelo fator região, sendo que próximo à junção amelodentinária observou-se os maiores valores $(206,7 \mathrm{KH})$, seguido pela região média do esmalte $(194,5 \mathrm{KH})$, com os menores valores de microdureza $(184,8 \mathrm{KH})$ na superfície do esmalte. Entretanto, a ausência de outros estudos na literatura específica acerca da avaliação da microdureza do esmalte de dentes decíduos em diferentes profundidades, após irradiação, não permite uma comparação direta dos resultados obtidos neste estudo.

O esmalte dental é organizado em prismas, cuja orientação determina o comportamento anisotrópico do esmalte e influencia suas propriedades mecânicas (Urabe et al., 2000; Giannini et al., 2004). Após irradiação cumulativa com 30 Gy e 60 Gy pode-se observar alterações morfológicas na estrutura do esmalte, por meio de MEV. Em comparação à amostra não irradiada, foi verificada uma desorganização crescente da estrutura prismática conforme a dose cumulativa de radioterapia aumentava, como descrito previamente para dentes bovinos (Jansma et al., 1988).

Embora a composição do esmalte seja essencialmente inorgânica, os danos iniciais da irradiação ocorrem na porção orgânica do esmalte, ou seja, no espaço interprismático, via produção de peróxido de hidrogênio e radicais livres de hidrogênio, a partir das moléculas de água que desnaturam os componentes orgânicos (Baker, 1982; Guy-Poyto e Pharoah, 1989). Como consequência, as propriedades mecânicas e a integridade do esmalte são afetadas (AlNawas et al., 2000), podendo inclusive provocar distúrbios de mineralização nos tecidos mineralizados (Knychalska-Karwan et al., 1988). 
Entretanto, a extrapolação clínica dos resultados de estudos in vitro ou in situ que avaliaram a estrutura, desmineralização e dissolução do esmalte de dentes irradiados deve ser cautelosa, tendo em vista os resultados contraditórios destas pesquisas. Aliado a esta divergência, deve-se considerar o fato de que é difícil reproduzir in vitro e in situ todas as alterações clínicas e as respostas individuais de cada paciente aos efeitos da radioterapia, dentre elas as diferenças no fluxo salivar, composição da microbiota bucal, alterações na dieta e dose de radiação (Jansma et al., 1988; Kielbassa, 2000; Kielbassa et al., 2006; Gernhardt et al., 2001; Soares et al., 2010; Soares et al., 2011).

De modo geral, a radiação ionizante no esmalte de dentes decíduos levou ao aumento da microdureza superficial possivelmente devido às alterações morfológicas, ou seja, desorganização da estrutura dos prismas de esmalte, com maior compactação de material inorgânico, observados no presente estudo pela MEV e aumento da porcentagem de íons cálcio e redução da porcentagem de oxigênio, observada na espectroscopia de energia dispersiva de raios $X$.

\subsection{ALTERAÇÔES NA DENTINA DE DENTES DECÍDUOS}

A dentina é um substrato biológico hidratado composto de $70 \%$ de material inorgânico, 18 \% de matriz orgânica e 12 \% de água (\% em peso), com várias propriedades e componentes estruturais, dependendo no local (Katchburian e Arana, 2004; Mjor, 2009), que conferem propriedades direcionais (anisotropia) ao tecido e tem efeitos sobre a sua resistência à tração (Carvalho et al., 2001; Giannini et al., 2004; Ryou et al., 2011) O conteúdo inorgânico da dentina é constituido por cristais de hidroxiapatita, enquanto a porção orgânica contém principalmente colágeno tipo I, frações de colágeno tipo III e V, glicoproteínas e proteoglicanos, além de proteínas não colágenas (Katchburian e Arana, 2004; Mjor, 2009).

No presente estudo, o conteúdo mineral da dentina de dentes decíduos foi quantificado com auxílio do EDX. Na dentina irradiada foi observado o valor médio de 48,86 \% de cálcio, 18,91 \% fósforo e 32,24 \% de oxigênio, enquanto na dentina não irradiada os valores médios encontrados foram 44,27 \% de cálcio, 17,55 \% de fósforo e 38,19 \% de oxigênio. Observa-se que na dentina irradiada o valor de Ca foi maior que na dentina não irradiada e do $\mathrm{O}$ foi menor, este fato pode ser devido à degradação proteica ocasionada pela irradiação e como à parte orgânica deste substrato é basicamente colágeno explica-se a diminuição do 0 . 
Com relação aos efeitos da radiação ionizante na microdureza longitudinal da dentina, pode-se observar que com aumento da dose houve uma diminuição significantemente da microdureza quando se utilizou as doses cumulativas de 10 a $40 \mathrm{~Gy}$. As doses $50 \mathrm{~Gy}$ e $60 \mathrm{~Gy}$ apresentaram valores semelhantes entre elas e semelhantes aos controles não irradiado. $\mathrm{Na}$ análise individual de cada região da dentina, pode-se observar que a irradiação influenciou apenas a microdureza longitudinal da região próxima à junção amelodentinária, que foi menor que a microdureza da mesma região em dentes não irradiados.

A redução da microdureza observada no presente estudo em dentes decíduos, é concordante com outros estudos prévios que utilizaram doses de radiação de até $70 \mathrm{~Gy}$, embora com protocolos de irradiação distintos (Markitziu et al., 1986; Kielbassa et al., 1997; Kielbassa, 2000). Por outro lado, doses de irradiação de 60 e 70 Gy foram incapazes de alterar a microdureza do esmalte e dentina irradiados in vitro, no estudo de Rahn et al. (1989).

A redução na microdureza da dentina irradiada poderia ser explicada, uma vez que as alterações nos componente orgânicos no interior dos túbulos dentinários são consideradas as principais razões pela diminuição da resistência física da dentina, após irradiação in vivo ou in vitro de dentes permanentes (Al- Nawas et al., 2000; Açil et al., 2007; Springer et al., 2005). A dentina contém $12 \%$ de conteúdo aquoso em volume (Katchburian e Arana, 2004; Mjor, 2009) o que permite maior produção de radicais livres e peróxido de hidrogênio em função da radiação (Fisher et al., 1971; Cole e Silver, 1963). Estes compostos são responsáveis pela desnaturação do conteúdo orgânico da dentina, resultando em menor estabilidade interna da dentina (Geoffroy e Tochan-Danglh, 1985; Cevc et al., 1972; Pioch et al., 1992), que provavelmente pode ser explicado pela diminuição do O no tecido.

Tendo em vista que os métodos de armazenamento dos dentes não foi padronizado nos diferentes estudos, é importante considerar que a degradação do conteúdo orgânico previamente à realização dos experimentos pode ter influenciado os resultados. No presente estudo, os dentes foram extraídos e imediatamente colocados em timol por 24 horas, lavados em água corrente e congelados a $-20{ }^{\circ} \mathrm{C}$, até o início dos experimentos.

Na MEV, observou-se alterações morfológicas na dentina de dentes decíduos após irradiação cumulativa com 30 Gy e 60 Gy. Em comparação à dentina não irradiada verificouse uma desorganização crescente, caracterizada por degradação da rede de colágeno e alteração na dentina intertubular e intratubular, conforme aumentou a dose cumulativa de radiação. Grötz et al. (1997) atribuíram a obliteração dos túbulos dentinários, em dentes permanentes irradiados, à degeneração dos processos odontoblásticos, sendo resultado do dano radiogênico direto às células, com redução do metabolismo, particularmente na área 
terminal dos odontoblastos. No presente estudo in vitro foi observada a desorganização do tecido dentinário possivelmente devido à desestruturação da dentinária intertubular e a degradação da rede de colágeno.

A alteração da estrutura dentinária de dentes permanentes irradiados foi observada previamente por Soares et al. (2010), ao estudarem o efeito da radiação ionizante sobre a resistência à tração da dentina em relação à localização e orientação dos túbulos dentinários. Terceiros molares obtidos de humanos foram submetidos à radiação ionizante com 60 Gy e avaliados por meio de testes de microtração, e comparados com dentes não irradiados. 0 tecido dentinário radicular e coronário não irradiado apresentou resistência à microtração significativamente maior, quando avaliados perpendicularmente à orientação dos túbulos. No entanto, quando os dentes foram irradiados, a orientação dos túbulos não influenciou a resistência à tração, indicando que a irradiação foi prejudicial aos componentes orgânicos e afetou as propriedades mecânicas da dentina. Como a irradiação de proteínas leva a mudanças em suas estruturas secundárias e terciárias, a irradiação provavelmente tem um efeito prejudicial sobre a hidratação das fibras colágenas pela ação de radicais livres (Chistiakov et al., 2008).

Diversos estudos in vitro ou in situ que avaliaram a desmineralização e a dissolução de esmalte e dentina de dentes permanentes irradiados mostraram resultados contraditórios. É importante mencionar que estes estudos não reproduzem de modo adequado todas as alterações clínicas, tampouco as respostas individuais de cada paciente aos efeitos da radioterapia, incluindo as diferenças no fluxo salivar, composição da microbiota bucal e alterações na dieta. Estes fatores permitem a maior proliferação de micro-organismos acidogênicos e cariogênicos (Streptococcus mutans, Lactobacillus e espécies de Candida), reduzindo a capacidade imunológica antibacteriana inerente à saliva. $\mathrm{O}$ pH salivar pósradiação diminui de 7,0 para 5,0, tornando-se definitivamente cariogênico (Stevenson-Moore e Epstein, 1993; Pankhurst et al., 1996; Al-Nawas et al., 2000, Al-Nawas e Grotz, 2006; Kielbassa et al., 2006). Como agravante da diminuição da quantidade de saliva, do pH salivar e da perda da capacidade tampão salivar, o conteúdo mineral do esmalte e da dentina pode sofrer dissolução facilmente (Shaw et al., 2000; Kielbassa et al., 2006; Sciubba e Goldenberg, 2006). Portanto, devido às limitações inerentes aos estudos in vitro, parece difícil avaliar, de um ponto de vista mais rigoroso, o risco aumentado à cárie de radiação com base apenas na desmineralização e ou quaisquer alterações estruturais do esmalte e da dentina irradiados (Jansma et al., 1988; Kielbassa, 2000; Gernhardt et al., 2001; Kielbassa et al., 2006, Soares et al., 2010; Soares et al., 2011). 
De acordo com os resultados do presente estudo, outros fatores que podem ser responsáveis pelo maior risco à cárie e instalação de "cárie de radiação", em dentes decíduos irradiados, possivelmente são o aumento da microdureza longitudinal do esmalte, aliadas as alterações morfológicas que ocorrem no esmalte e dentina e à alteração no conteúdo de oxigênio e cálcio nesses substratos.

Estudos adicionais são necessários, em outros níveis de pesquisa e avaliando outras variáveis, incluindo estudos clínicos, para comprovar que a irradiação levou a alterações na estrutura do substrato dental, que pode ocasionar diversos problemas odontológicos, em pacientes infantis oncológicos. 


\section{CONCLUSÃo}

Dentro das condições experimentais utilizadas, pode-se concluir que a irradiação de dentes decíduos com Co-60:

- Influenciou a microdureza longitudinal do esmalte e da dentina, dependendo da dose e da área irradiada. No esmalte como um todo, a microdureza aumentou após a dose cumulativa de $60 \mathrm{~Gy}$, independente da área analisada. Na dentina, não houve alteração dos valores de microdureza após irradiação, independente da área analisada.

- Ocasionou a desorganização morfológica do esmalte e da dentina, que passaram a apresentar uma superfície amorfa, com maior dificuldade de identificação dos prismas de esmalte e túbulos dentinários, respectivamente.

- Reduziu a porcentagem de oxigênio e aumentou a porcentagem de cálcio no esmalte e na dentina irradiados. 


\section{REFERÊNCIAS}

Açil Y, Springer IN, Niehoff P, Gassling V, Warnke PH, Açmaz S, Sönmez TT, Kimmig B, Lefteris $\mathrm{V}$, Wiltfang J. Proof of direct radiogenic destruction of collagen in vitro. Strahlenther Onkol 2007;183(7):374-9.

Adelstein DJ. Systemic chemotherapy for squamous cell head and neck cancer. Expert Opin Pharmacother 2003;4(12):2151-63.

Amaechi BT, Higham SM. In vitro remineralisation of eroded enamel lesions by saliva. J Dent 2001;29(5):371-6.

Andrews N, Griffiths C. Dental complications of head and neck radiotherapy:Part 2. Aust Dent J 2001;46(3):174-82.

Aggarwal V. An in vitro evaluation of effect of ionizing radiotherapy on push-out strength of fiber posts under cyclic loading. J Endod 2009;35(5):695-8.

Al-Nawas B, Grötz KA, Rose E, Duschner H, Kann P, Wagner W. Using ultrasound transmission velocity to analyse the mechanical properties of teeth after in vitro, in situ, and in vivo irradiation. Clin Oral Investig 2000;4(3):168-72.

Al-Nawas B, Grötz KA. Prospective study of the long term change of the oral flora after radiation therapy. Support Care Cancer 2006;14(3):291-6.

Anneroth G, Holm LE, Karlsson G. The effect of radiation on teeth. A clinical, histologic and microradiographic study. Int J Oral Surg 1985;14(3):269-74.

Baker DG. The radiobiological basis for tissue reactions in the oral cavity following therapeutic x-irradiation. A review. Arch Otolaryngol 1982;108(1):21-4.

Brudevold F, Savory A, Gardner De, Spinelli M, Speirs R. A study of acidulated fluoride solutions. I. In vitro effects on enamel. Arch Oral Biol 1963;(8):167-77. 
Bulucu B, Avsar A, Demiryürek EO, Yesilyurt C. Effect of radiotherapy on the microleakage of adhesive systems. J Adhes Dent 2009;11(4):305-9.

Cardoso MFA, Novikoff S, Tresso A, Segreto RA, Cervantes O. Prevenção e controle das sequelas bucais em paciente irradiados por tumores de cabeça e pescoço. Radiol Bras 2005;38(2):107-115.

Carvalho RM, Fernandes CA, Villanueva R, Wang L, Pashley DH. Tensile strength of human dentin as a function of tubule orientation and density. J Adhes Dent 2001;3(4):309-14.

Cervc P, Schara M, Ravnik C. Electron paramagnetic resonance study of irradiated tooth enamel. Radiat Res 1972;51(3):581-9.

Chaachouay H, Ohneseit P, Toulany M, Kehlbach R, Multhoff G, Rodemann HP. Autophagy contributes to resistance of tumor cells to ionizing radiation. Radiother Oncol 2011;Jun 29.

Chistiakov DA, Voronova NV, Chistiakov PA. Genetic variations in DNA repair genes, radiosensitivity to cancer and susceptibility to acute tissue reactions in radiotherapy-treated cancer patients. Acta Oncol 2008;47(5):809-24.

Craddock HL. Treatment and maintenance of a dentate patient with 'radiation caries'. Dent Update 2006;33(8):462-8.

Craddock HL. Treatment and maintenance of a dentate patient with 'radiation caries'. SADJ 2008;63(10):532,534-7.

Cole $\mathrm{T}$, Silver $\mathrm{AH}$. Production of hydrogen atoms in teeth by $\mathrm{x}$-irradiation. Nature $1963 ; 16: 200: 700-1$.

Davis WB. Reduction in dentin wear resistance by irradiation and effects of storage in aqueous media. J Dent Res 1975;54:1078-1081.

De Menezes Oliveira MA, Torres CP, Gomes-Silva JM, Chinelatti MA, De Menezes FC, PalmaDibb RG, Borsatto MC. Microstructure and mineral composition of dental enamel of permanent and deciduous teeth. Microsc Res Tech 2010;73(5):572-7. 
Engelmeier RL, King GE. Complications of head and neck radiation therapy and their management. J Prosthet Dent 1983;49(4):514-22.

Fava M, Watanabe I, Moraes FF, Costa LRRS. Prismless enamel in human non erupted deciduous molar teeth: a scanning eletron microscopic study. Rev Odontol Univ São Paulo $1997 ; 11(4): 239-243$.

Fava M, Watanabe I, Moraes FF. Fine structure and histometry of the enamel prismless layer of unerupted third molar teeth. Rev Chil Anat 1993;11:19-24.

Fisher BV, Morgan RE, Phillips GO, Wardale HW. Radiation damage in calcium phosphates and collagen: An interpretation of ESR spectra. Radiat Res 1971;46:229-235.

Fotos PG, Diaz-Arnold AM, Williams VD. Effect of microbial contamination and $\mathrm{pH}$ changes in storage solutions during in vitro assays of bonding agents. Dent Mater 1990;6(3):154-7.

Fränzel W, Gerlach R. The irradiation action on human dental tissue by X-rays and electrons--a nanoindenter study. Z Med Phys 2009;19(1):5-10.

Geoffroy M, Tochan-Danglh' HJ. Long-lived radicals in irradiated apatites: an e.s.r. study of apatite samples treated with CO2. Int J Radiat Bio 1985;4:621-633.20.

Gernhardt CR, Kielbassa AM, Hahn P, Schaller HG: Tensile bond strengths of four different dentin adhesives on irradiated and non-irradiated human dentin in vitro. J Oral Rehabil $2001 ; 28: 814-820$.

Giannini M, Soares CJ, de Carvalho RM. Ultimate tensile strength of tooth structures. Dent Mater 2004;20(4):322-9.

Grötz KA, Duschner H, Kutzner J, Thelen M, Wagner W. New evidence for the etiology of socalled radiation caries. Proof for directed radiogenic damage od the enamel-dentin junction. Strahlenther Onkol 1997;173(12):668-76.

Grötz KA, Duschner H, Kutzner J, Thelen M, Wagner W. Histotomography studies of direct radiogenic dental enamel changes. Mund Kiefer Gesichtschir 1998;2(2):85-90. 
Grötz KA, Riesenbeck D, Brahm R, Seegenschmiedt MH, al-Nawas B, Dörr W, Kutzner J, Willich $\mathrm{N}$, Thelen $\mathrm{M}$, Wagner $\mathrm{W}$. Chronic radiation effects on dental hard tissue (radiation caries). Classification and therapeutic strategies. Strahlenther Onkol 2001;177(2):96-104.

Guy Poyto H, Pharoah MJ, Oral radiology. Toronto, Philadelphia: B, C, Decker, 1989;17-19.

Gwinnett AJ. Structure and composition of enamel. Oper Dent 1992;5:10-7.

Hannig M, Dounis E, Henning T, Apitz N, Stösser L. Does irradiation affect the protein composition of saliva? Clin Oral Investig 2006;10(1):61-5.

Huber MA, Terezhalmy GT. The head and neck radiation oncology patient. Quintessence Int 2003;34(9):693-717.

Instituto Nacional do Câncer. Disponível em: http// www.inca.gov.br/estimativa/2010. Acesso em 29/11/2009.

Jansma J, Borggreven JM, Driessens FC, 's-Gravenmade EJ. Effect of X-ray irradiation on the permeability of bovine dental enamel. Caries Res 1990;24(3):164-8.

Jansma J, Buskes JA, Vissink A, Mehta DM, Gravenmade EJ. The effect of X-ray irradiation on the demineralization of bovine dental enamel. A constant composition study. Caries Res 1988;22(4):199-203.

Jansma J, Vissink A, Jongebloed WL, Retief DH, Johannes 's-Gravenmade E.Natural and induced radiation caries: A SEM study. Am J Dent 1993;6(3):130-6.

Jervoe P. X-ray diffraction investigation on the effect of experimental and in situ radiation on mature human teeth. A preliminary report. Acta Odontol Scand 1970;28(5):623-31.

Jham BC, da Silva Freire AR. Oral complications of radiotherapy in the head and neck. Braz J Otorhinolaryngol 2006;72(5):704-8. 
Jham BC, Reis PM, Miranda EL, Lopes RC, Carvalho AL, Scheper MA, Freire AR. Oral health status of 207 head and neck cancer patients before, during and after radiotherapy. Clin Oral Investig 2008;12(1):19-24.

Joyston-Bechal S. The effect of X-radiation on the susceptibility of enamel to an artificial caries-like attack in vitro. J Dent 1985;13(1):41-4.

Katchburian E, Arana V. Esmalte. In:Histologia e embriologia oral : texto - atlas correlações clínicas. São Paulo: Panamericana, 2005, cap. 8: 237- 279.

Kielbassa AM, Beetz I, Schendera A, Hellwig E. Irradiation effects on microhardness of fluoridated and non-fluoridated bovine dentin. Eur J Oral Sci 1997;105(5 Pt 1):444-7.

Kielbassa AM, Wrbas KT, Schulte-Mönting J, Hellwig E. Correlation of transversal microradiography and microhardness on in situ-induced demineralization in irradiated and nonirradiated human dental enamel. Arch Oral Biol 1999;44(3):243-51.

Kielbassa AM. In situ induced demineralization in irradiated and non-irradiated human dentin. Eur J Oral Sci 2000;108(3):214-21.

Kielbassa AM, Schendera A, Schulte-Mönting J. Microradiographic and microscopic studies on in situ induced initial caries in irradiated and nonirradiated dental enamel. Caries Res 2000;34(1):41-7.

Kielbassa AM, Hinkelbein W, Hellwig E, Meyer-Lückel $H$. Radiation-related damage to dentition. Lancet Oncol 2006;7(4):326-35.

Knychalska-Karwan Z, Pawlicki R, Karwan T. Structural and microanalytical changes in dentition after radiotherapy applied in cases of tumour in the oral cavity region. Folia Histochem Cytobiol 1988;26(1):25-32.

Langland OE, Langlais RP. Princípios do Diagnóstico por Imagem em Odontologia. São Paulo: Ed Santos; 2002. 
Lôbo ALG, Martins GB. Consequências da Radioterapia na Região de Cabeça e Pescoço: Uma Revisão da Literatura. Rev Port Estomatol Cir Maxilofac 2009;50(4):251-255.

Markitziu A, Gedalia I, Rajstein J, Grajover R, Yarshanski O, Weshler Z. In vitro irradiation effects on hardness and solubility of human enamel and dentin pretreated with fluoride. Clinical Prevent Dent 1986;8(4):4-7.

Meckel AH, Griebstein WJ, Neal RJ. Structure of mature human dental enamel as observed by electron microscopy.Arch Oral Biol 1965;10(5):775-83.

Mjör IA. Dentin permeability: the basis for understanding pulp reactions and adhesive technology. Braz Dent J 2009;20(1):3-16.

Novaes PERS. Radioterapia. In: Brentani MM, Coelho FRG, Iyeyasu H, Kowalski LP, editors. Bases da oncologia. 1 ed. São Paulo: ED. Marina;1998.

Ohrn KE, Wahlin YB, Sjödén PO. Oral status during radiotherapy and chemotherapy: a descriptive study of patient experiences and the occurrence of oral complications. Support Care Cancer 2001;9(4):247-57.

Otmani N. Oral and maxillofacial side effects of radiation therapy on children. J Can Dent Assoc 2007;73(3):257-61.

Pankhurst CL, Dunne SM, Rogers JO. Restorative dentistry in the patient with dry mouth: Part 2. Problems and solutions. Dent Update 1996;23(3):110-14.

Pioch T, Golfels D, Staehle HJ. An experimental study of the stability of irradiated teeth in the region of the dentinoenamel junction. Endod Dent Traumatol 1992;8(6):241-4.

Poyton HG. The effects of radiation on teeth. Oral Surg Oral Med Oral Pathol 1968;26(5):639-46.

Ramirez-Amador V, Silverman S Jr, Mayer P, Tyler M, Quivey J. Candidal colonization and oral candidiasis in patients undergoing oral and pharyngeal radiation therapy. Oral Surg Oral Med Oral Pathol Oral Radiol Endod 1997;84(2):149-53. 
Rahn R, Kocjancic B, Urban T, Manegold R. In vitro study of causes of radiation caries. ZWR 1989;98(8):701-3.

Saleh J, Willke LW, Bassani IA, Kraether L, Molz RF, Santos LA. Obtenção e avaliação de hidroxiapatita in vivo. XVI Congresso Brasileiro de Engenharia e Ciência dos Matériais, Porto Alegre, 2004.

Sciubba JJ, Goldenberg D. Oral complications of radiotherapy. Lancet Oncol 2006;7(2):17583.

Shannon IL, Wescott WB, Starcke EN, Mira J. Laboratory study of cobalt-60-irradiated human dental enamel. J Oral Med 1978;33(1):23-7.

Shaw MJ, Kumar ND, Duggal M, Fiske J, Lewis DA, Kinsella T, Nisbet T. Oral management of patients following oncology treatment: literature review. $\mathrm{Br} J$ OralMaxillofac Surg 2000;38(5):519-24.

Shibuya K, Mathers CD, Boschi-Pinto C, Lopez AD, Murray CJ. Global and regional estimates of cancer mortality and incidence by site: II. Results for the global burden of disease 2000. BMC Cancer 2002;26(2):37.

Silva AR, Alves FA, Antunes A, Goes MF, Lopes MA. Patterns of demineralization and dentin reactions in radiation-related caries. Caries Res 2009; 43(1):43-9. (a)

Silva AR, Alves FA, Berger SB, Giannini M, Goes MF, Lopes MA. Radiation-related caries and early restoration failure in head and neck cancer patients. A polarized light microscopy and scanning electron microscopy study. Support Care Cancer 2009;17. (b)

Silverman S Jr. Oral cancer: complications of therapy. Oral Surg Oral Med Oral Pathol Oral Radiol Endod 1999;88(2):122-6.

Soares CJ, Neiva NA, Soares PB, Dechichi P, Novais VR, Naves LZ, Marques MR. Effects of chlorhexidine and fluoride on irradiated enamel and dentin. J Dent Res 2011;90(5):659-64. 
Soares CJ, Castro CG, Neiva NA, Soares PV, Santos-Filho PC, Naves LZ, Pereira PN. Effect of gamma irradiation on ultimate tensile strength of enamel and dentin. J Dent Res 2010;89(2):159-64.

Springer IN, Niehoff P, Warnke PH, Böcek G, Kovács G, Suhr M, Wiltfang J, Açil Y. Radiation caries--radiogenic destruction of dental collagen. Oral Oncol 2005;41(7):723-8.

Stack MV. Organic constituents of enamel. J Am Dent Assoc 1954;48(3):297-306.

Stevenson-Moore P, Epstein JB. The management of teeth in irradiated sites. Eur J Cancer B Oral Oncol 1993;29B(1):39-43.

Sulaiman F, Huryn JM, Zlotolow IM. Dental extractions in the irradiated head and neck patient: a retrospective analysis of Memorial Sloan-Kettering Cancer Center protocols, criteria, and end results. J Oral Maxillofac Surg 2003;61(10):1123-31.

Urabe I, Nakajima S, Sano H, Tagami J. Physical properties of the dentin-enamel junction region. Am J Dent 2000;13(3):129-35.

Vissink A, Jansma J, Spijkervet FK, Burlage FR, Coppes RP. Oral sequelae of head and neck radiotherapy. Crit Rev Oral Biol Med 2003;14(3):199-212.

Vuotila T, Ylikontiola L, Sorsa T, Luoto H, Hanemaaijer R, Salo T, Tjäderhane L. The relationship between MMPs and $\mathrm{pH}$ in whole saliva of radiated head and neck cancer patients. J Oral Pathol Med 2002;31(6):329-38. 


\section{Anexo 1}

\section{UNIVERSIDADE DE SÃO PAULO}

Faculdade de Odontologia de Ribeirão Preto Comitê de Ética em Pesquisa

Of.ATAC.CEP/03511/FORP-USP/18.02.2011 CHLS/fdc

Ref. processo n. ${ }^{\circ}$ 2010.1.1512.58.9 CAAE n. ${ }^{\circ} 0100.0 .138 .000-10$

Senhor(a) Pesquisador(a):

Informamos que o Comitê de Ética em Pesquisa, em sua $117^{a}$ Sessão, realizada em 17 de fevereiro de 2011, aprovou o desenvolvimento do projeto de pesquisa envolvendo seres humanos, intitulado "Avaliação das propriedades do substrato dental de dentes decíduos após irradiação com Co-60".

$\mathrm{Na}$ oportunidade, lembramos da necessidade de serem entregues, na secretaria do CEP, O Relatório Parcial em 17/10/2011 e o Relatório Final em 17/05/2012, com os respectivos formulários preenchidos pelo pesquisador responsável.

Lembramos ainda que, quando da submissão do relatório a este Comitê, quaisquer inclusões ou modificações no projeto original deverão ser comunicadas e justificadas ao CEP, através do formulário supracitado.

PROFA. DRA. CLÁUdia HELENA LOVATO DA SILVA

Coordenadora do Comitê de Ética em Pesquisa

IImo(a). Sr(a).

PROF(A). DR(A). ALEXANDRA MUSSOLINO DE QUEIROZ

Departamento de Clínica Infantil, Odontologia Preventiva e Social

desta Faculdade 